\title{
Ab initio modeling of the bonding of benzotriazole corrosion inhibitor to reduced and oxidized copper surfaces
}

\author{
Anton Kokalj* \\ Received 11th December 2014, Accepted 2nd February 2015 \\ DOI: $10.1039 / c 4 f d 00257 a$
}

\begin{abstract}
The bonding of benzotriazole-an outstanding corrosion inhibitor for copper-on reduced and oxidized copper surfaces is discussed on the basis of density functional theory (DFT) calculations. Calculations reveal that benzotriazole is able to bond with oxide-free and oxidized copper surfaces and on both of them it bonds significantly stronger to coordinatively unsaturated $\mathrm{Cu}$ sites. This suggests that benzotriazole is able to passivate the reactive under-coordinated surface sites that are plausible microscopic sites for corrosion attack. Benzotriazole can adsorb in a variety of different forms, yet it forms a strong molecule-surface bond only in deprotonated form. The bonding is even stronger when the deprotonated form is incorporated into organometallic adcomplexes. This is consistent with existing experimental evidence that benzotriazole inhibits corrosion by forming protective organometallic complexes. It is further shown that adsorption of benzotriazole considerably reduces the metal work function, which is a consequence of a large permanent molecular dipole and a properly oriented adsorption structure. It is argued that such a pronounced effect on the work function might be relevant for corrosion inhibition, because it should diminish the anodic corrosion reaction, which is consistent with existing experimental evidence that benzotriazole, although a mixed type inhibitor, predominantly affects the anodic reaction.
\end{abstract}

\section{Introduction}

There are various ways of corrosion protection and one of them is by means of corrosion inhibitors, which are substances that have the ability to considerably slow down the corrosion of metals and alloys by decreasing the rate of corrosion processes. Among efficient corrosion inhibitors are also organic molecules. It is commonly believed that strong interaction between an organic inhibitor molecule and a substrate is very important for achieving the inhibitory effect. ${ }^{1-3}$ In particular, Bockris stated that organic molecules must be adsorbed to become inhibitors. ${ }^{3}$ 
Despite the soundness of the strong adsorption premise, DFT (density functional theory) calculations have revealed-contrary to what might have been intuitively expected - that some outstanding inhibitor molecules, such as benzotriazole and several other azoles, interact only weakly in their intact form with substrates. ${ }^{4-6}$ For example, an intact benzotriazole molecule bonds only by about $0.5 \mathrm{eV}$ to a $\mathrm{Cu}(111)$ surface, ${ }^{5,6}$ which is similar in strength to solvation interaction between benzotriazole and water. ${ }^{7,8}$ This implies that the net adsorption energy at the water/solid interface should be rather small, which may seem surprising, because if the bonding is that weak then aggressive corrosive species would easily replace benzotriazole from the surface (if it would adsorb at all). How then, can benzotriazole act against corrosion?

Benzotriazole has been used for a long time as one of the most efficient copper corrosion inhibitors ${ }^{\mathbf{1 9 - 1 1}}$ and there are numerous studies of its inhibition action on copper. Nevertheless, Finšgar and Milošev stated in a recent review: ${ }^{11}$ “... the exact mechanism of benzotriazole action on copper materials still remains to be elucidated. It is important to clarify why benzotriazole, and not other organic molecules with similar electronic structure, imparts corrosion protection. The answer to this question will provide the basis for predicting new and more effective corrosion inhibitors."

The aim of this paper is to discuss the adsorption behavior of benzotriazoleas elucidated by DFT calculations-on reduced and oxidized copper surfaces (for the latter only the $\mathrm{Cu}(\mathrm{I})$ oxidation state is currently considered). The issue seems relevant, because controversial suggestions exist in the literature, ${ }^{\mathbf{1 1}}$ i.e., according to some researchers the presence of oxides is important, ${ }^{12-14}$ while others claimed that their presence is not needed for the adsorption of benzotriazole. ${ }^{15,16}$ It has to be emphasized that adsorption behavior is not synonymous with the mechanism of corrosion inhibition, yet it may nevertheless provide some useful information and insight. The literature is replete with numerous suggestions about possible adsorption mechanisms of benzotriazole on copper. ${ }^{11}$ There are at least two reasons of why this is so: the first is due to complexity of the investigated system. The interpretation of experimental data therefore involves various degree of assumptions and different assumptions may lead to different conclusions. The second reason is due to-as is argued in this paper-nontrivial adsorption behavior of benzotriazole, because it can adsorb in a variety of different forms. It all depends on the details and perhaps this is one of the strengths of benzotriazole and other inhibitor molecules; depending on different conditions they will adopt one of several possible forms and thus sustain various situations.

There are several important points to keep in mind when considering the results presented in this paper. The most important is that due to obvious modeling reasons the presented results refer to the solid/vacuum interface (solvent effects are estimated a posteriori when explicitly stated so), whereas in the context of corrosion the solid/water is the relevant interface. Apart from the fact that solvent considerably affects the energetics of adsorption, there is another distinction between the adsorption at solid/vacuum and solid/water interfaces. The adsorption at the latter is competitive (or substitutional), because the surface is always covered with solvent molecules and other possible species. So a given molecule will adsorb only if its adsorption is competitive enough to substitute other species from the surface. In contrast, at the solid/vacuum interface the surface is clean and the molecule adsorbs readily (say that surface temperature is low enough) unless its interaction with the surface is repulsive. 
The paper is organized as follows: Section 2 contains a brief description of computational method along with some definitions, while Section 3 deals with bare metallic copper surfaces and reviews the pertinent computational DFT studies. These data are put into a new context and the relevance of the work function reduction upon adsorption of inhibitor is emphasized. Oxidized copper surfaces are considered in Section 4, where significant new results are presented. Section 5 finally contains the conclusions.

\section{Technical details}

\subsection{Definitions}

Term "copper surface" shall implicitly indicate the bare (reduced) metallic copper surface (oxidation state of 0 ); the oxidized surface shall be explicitly referred to as "oxidized". The labels BTAH and BTA indicate the intact and dissociated (without $\mathrm{H} 1$ atom/proton) benzotriazole molecule, respectively (atom numbering and skeleton structures of neutral BTAH molecule and deprotonated $\mathrm{BTA}^{-}$anion are shown in Scheme 1). $\mathrm{BTAH}_{(\mathrm{g})}, \mathrm{BTAH}_{(\text {solv })}, \mathrm{BTAH}_{(\mathrm{ads})}$ stand for gas-phase, solvated, and adsorbed molecule, respectively (and analogously for other species). Notation BTA-Cu refers to organometallic complex, while the stand-alone chemisorbed form is designated as $\mathrm{BTA}_{(\mathrm{ads})}$. Other labels are defined when first used.

\subsection{Computational}

DFT calculations were performed with the plane-wave pseudo-potential method as implemented in the PWscf code from the Quantum ESPRESSO distribution, ${ }^{17}$ using the ultrasoft pseudopotentials ${ }^{18}$ and plane wave basis set with a kinetic energy cut-off $=30$ Ry (240 Ry for the charge-density), while molecular graphics were produced by the $X C R Y S D E N^{19}$ graphical package. Calculations were performed with $\mathrm{PBE}^{20}$ and reparametrized $\mathrm{PBE}-\mathrm{D}^{\prime}$ energy functionals; the former was used for chemisorption and the latter for parallel physisorption modes. PBE- $\mathrm{D}^{\prime}$ includes a semi-empirical dispersion correction of Grimme, ${ }^{21,22}$ which was reparametrized $^{23}$ to match the experimental adsorption energy of benzene on $\mathrm{Cu}(111)$. $\mathrm{Cu}$ surfaces were modeled by periodic slabs with the in-plane lattice spacing fixed at the calculated equilibrium Cu bulk lattice parameter ( $3.67 \AA$ for $\mathrm{PBE}^{24}$ and $3.64 \AA$ for PBE- ${ }^{\prime 23}$ ). For $\mathrm{Cu}_{2} \mathrm{O}$ surfaces, the PBE calculated equilibrium bulk lattice parameter of $4.35 \AA$ was used. Spin polarization was used when needed. For further computational details see our previous publications, in particular ref. 8 and also ref. 7.

Molecular adsorption energies (at solid/vacuum interface) were calculated as:

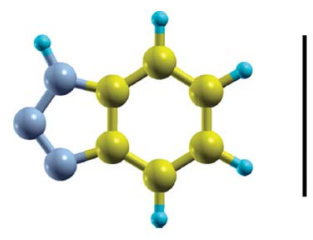

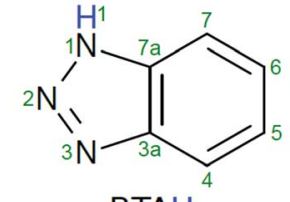

$\mathrm{BTAH}$

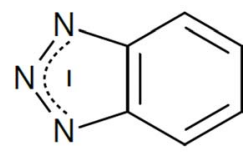

BTA $^{-}$

Scheme 1 Skeleton structures of neutral BTAH (middle) and its deprotonated BTA ${ }^{-}$form (right). Numbering of atoms is also indicated. Ball-and-stick model of BTAH is shown on the left to indicate the respective atom coloring. 


$$
E_{\mathrm{ads}}=E_{\mathrm{A} / \mathrm{surf}}-\left(E_{\mathrm{surf}}+E_{\mathrm{A}}\right)
$$

where the subscript A stands for adsorbate; $E_{\mathrm{A}}, E_{\mathrm{surf}}$, and $E_{\mathrm{A} / \text { surf }}$ are the total energies of isolated adsorbate (molecule or atom), $\mathrm{Cu}$ or $\mathrm{Cu}_{2} \mathrm{O}$ slab, and adsorbate/ slab system, respectively. The use of charged species was avoided in calculations employing periodic boundary conditions, where the long range Coulomb interactions dictate the use of charge neutrality. The adsorption (binding) energies of deprotonated $\mathrm{BTA}^{-}, \mathrm{Cl}^{-}$, and $\mathrm{H}^{+}$are therefore calculated with respect to isolated radicals $\left(\mathrm{BTA}^{\odot}, \mathrm{Cl}\right.$, and $\left.\mathrm{H}\right)$ and are designated as $E_{\mathrm{b}}^{\odot}$. Symbol $\odot$ is used to indicate the radical nature of the initial state. Subscript "b" is used in favor of "ads" to remind that binding energy of $\mathrm{BTA}_{(\mathrm{ads})}$ is measured with respect to isolated $\mathrm{BTA}^{\odot}$ (and not BTAH) and that of $\mathrm{Cl}_{(\text {ads) }}$ and $\mathrm{H}_{(\text {ads })}$ with respect to isolated $\mathrm{Cl}$ and $\mathrm{H}$ (and not $\mathrm{Cl}_{2}$ and $\mathrm{H}_{2}$ molecules). The $E_{\mathrm{b}}^{\odot}$ therefore measures the binding energy of these radicals to the surface. On metal surfaces, the binding energy can be recalculated with respect to anion in the initial state as: $E_{\mathrm{b}}{ }^{(-)}=E_{\mathrm{b}}^{\odot}+\mathrm{EA}^{\odot}-\Phi$, where $\mathrm{EA}^{\odot}$ is the electron affinity of corresponding radical and $\Phi$ is a work function (for cations the equation is: $E_{\mathrm{b}}{ }^{(+)}=E_{\mathrm{b}}^{\odot}-\mathrm{IP}^{\odot}+\Phi$, where $\mathrm{IP}^{\odot}$ is the ionization potential or respective radical). Analogously to $E_{\mathrm{b}}^{\odot}$, also the $E_{\text {ads }}$ of $\mathrm{BTAH}_{(\mathrm{ads})}$ is occasionally labeled as $E_{\mathrm{b}}$, in particular, when the molecule-surface binding is of primary concern.

\section{Adsorption of benzotriazole on reduced copper surfaces: bare $\mathrm{Cu}(h k l)$ and defects thereon}

Adsorption structures of benzotriazole on bare copper surfaces have been studied in detail by means of DFT calculations..$^{5-8,23,25-28}$ The main findings of these studies are briefly explained below (Section 3.1 and, in part, also 3.2 ) to put them in context for the current discussion paper.

\subsection{Description of various DFT identified adsorption modes}

Benzotriazole can adsorb either molecularly as $\mathrm{BTAH}_{(\mathrm{ads})}$ or dissociatively as $\mathrm{BTA}_{(\mathrm{ads})}$ $+\mathrm{H}_{(\mathrm{ads})}$ (cleavage of N1-H bond). While the $\mathrm{BTAH}_{(\mathrm{ads})}$ bonds weakly, the $\mathrm{BTA}_{(\mathrm{ads})}$ is strongly chemisorbed on copper surfaces. The calculated activation energy of dissociation for weakly chemisorbed BTAH is about $1.1 \mathrm{eV}$ on $\mathrm{Cu}(111)$, but on more open surfaces and step-edge defects the activation energy decreases below $1 \mathrm{eV}^{27}$ Dissociative adsorption of benzotriazole is experimentally well established, because it has often been observed that the $\mathrm{H} 1$ atom of benzotriazole is removed upon chemisorption on copper surfaces even under ultra high vacuum conditions..$^{15,28-31}$

Structures of different identified adsorption modes of $\mathrm{BTAH}_{(\mathrm{ads})}$ and $\mathrm{BTA}_{(\mathrm{ads})}$ are shown in Fig. 1 and binding energies as a function of coordination number of surface $\mathrm{Cu}$ atoms involved in the adsorption site are shown in Fig. 2.

3.1.1 Adsorption forms of BTAH $_{(\mathbf{a d s})}$. BTAH can either weakly chemisorb in an upright geometry $\left(\mathrm{BTAH}_{\perp}\right)$ via triazole nitrogen atoms with the $\mathrm{N}-\mathrm{Cu}$ distances of about 2.1 $\AA$ (Fig. 1a) or physisorb $\dagger$ nearly parallel $\left(\mathrm{BTAH}_{\|}\right)$to copper surfaces

$\dagger$ Terms chemisorption and physisorption refer to the type of molecule-surface interaction and not to the scale of the interaction energy. Molecule-surface bond length is a good descriptor to distinguish between the two. For chemisorption the benzotriazole-surface distances are about $2 \AA$, whereas for physisorption the distances are about $3 \AA$ as inferred from respective covalent and van der Waals radii. ${ }^{23}$ 


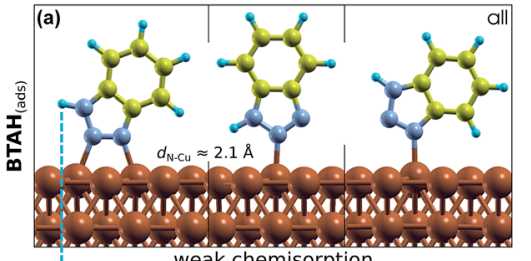

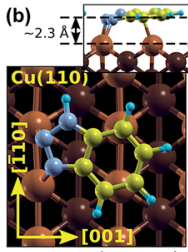

apparent chem+phys

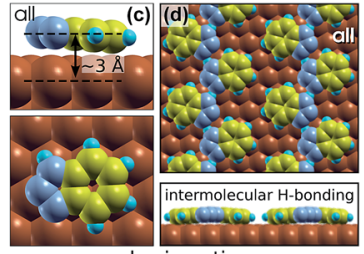

physisorption

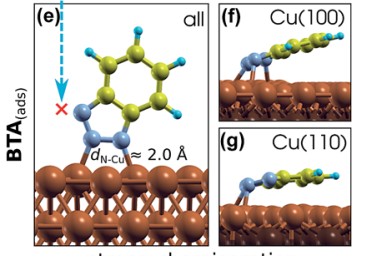

strong chemisorption
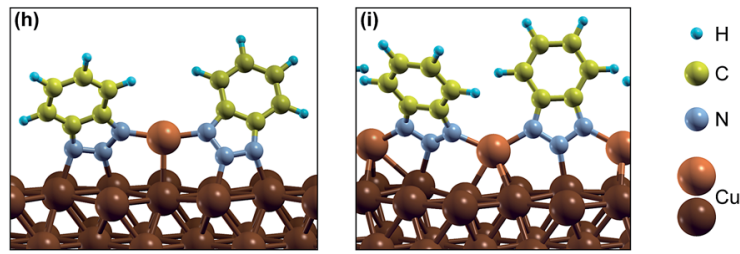

organometallic complexation - $\left[\mathrm{BTA}_{x} \mathrm{Cu}_{y}\right]$

Fig. 1 Various adsorption forms of benzotriazole on copper surfaces identified by means of DFT calculations ${ }^{5-8,23,25}$ (label "all" indicates that the form exists on all (several) $\mathrm{Cu}$

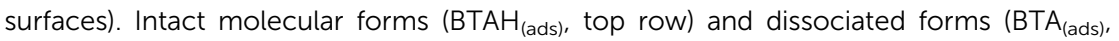
bottom row). (a) Weakly chemisorbed modes of BTAH bonded perpendicularly to the surface via triazole nitrogen atoms $\left(d_{\mathrm{N}-\mathrm{Cu}}\right.$ stands for $\mathrm{N}-\mathrm{Cu}$ bond length). ${ }^{5,6}$ (b) More strongly bonded parallel adsorption mode of BTAH on $\mathrm{Cu}(110)$ that is roughly oriented along the [001] direction; this mode was ascribed as apparent chemisorption + physisorption mode (labeled as "apparent chem + phys"). ${ }^{6}$ (c) Physisorption mode with BTAH molecular plane nearly parallel to the surface ${ }^{6,7}$ and (d) intermolecular $\mathrm{H}$-bonded networks of physisorbed $\mathrm{BTAH}_{7}^{7}$ this lateral $\mathrm{H}$-bonding stabilizes the physisorbed $\mathrm{BTAH}$ by about 0.5 $\mathrm{eV}$. (e) Strongly chemisorbed BTA (ads) $_{\text {b }}$ bonded perpendicularly to the surface; ${ }^{7,8}$ on $\mathrm{Cu}(100)$ and $\mathrm{Cu}(110)$ also highly tilted ( $\mathrm{f}$ ) and almost parallel $(\mathrm{g})$ variants were identified. ${ }^{8}$ ( $\mathrm{h}$ and $\mathrm{i}$ ) Benzotriazole-copper organometallic complexes: (h) [BTA-Cu-BTA] dimer ${ }^{25}$ and (i) $[\mathrm{BTA}-\mathrm{Cu}]_{n}$ polymer. $^{7}$

(Fig. 1c) with the molecule-surface height ranging from about $2.6 \AA$ on $\mathrm{Cu}(110)$ to 3 $\AA$ on $\mathrm{Cu}(111) .{ }^{6}$ While the adsorption bonding of $\mathrm{BTAH}_{\perp}$ becomes stronger as passing from densely packed $\mathrm{Cu}(111)$ to more open surfaces and low coordinated defects, the physisorption energy is similar on all three low Miller index surfaces (Fig. 2); ${ }^{6}$ a notable exception for the latter is the so-called apparent chemisorption + physisorption mode on $\mathrm{Cu}(110)$ (Fig. 1b), which adsorbs significantly stronger (Fig. 2). ${ }^{6}$

3.1.2 Adsorption forms of $\mathbf{B T A}_{(\mathrm{ads})}$. In contrast to intact $\mathrm{BTAH}_{(\mathrm{ads})}$, dissociated $\mathrm{BTA}_{(\mathrm{ads})}$ strongly bonds to copper surfaces and the magnitude of chemisorption energy increases as the coordination number of surface $\mathrm{Cu}$ atoms involved in the adsorption site decreases (Fig. 2). ${ }^{8}$ Dissociated benzotriazole can also form organometallic complexes on surfaces of copper (Fig. 1h and i); these complexes are specifically addressed in Section 3.4.

\subsection{Adsorption characteristics}

Adsorption forms of benzotriazole can be classified into four types: (i) weakly chemisorbed $\mathrm{BTAH}_{(\mathrm{ads})}$, (ii) physisorbed $\mathrm{BTAH}_{(\mathrm{ads})}$ (including the H-bonding networks of Fig. 1d), (iii) stand-alone strongly chemisorbed BTA $_{(\mathrm{ads})}$, and (iv) BTA$\mathrm{Cu}$ adcomplexes. These four types display rather different adsorption features and 


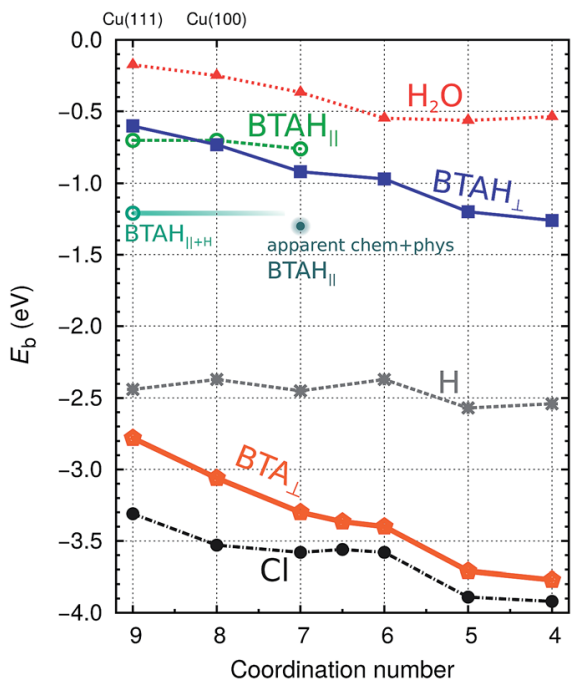

Fig. 2 Dependence of low coverage adsorption (binding) energies of BTAH, ${ }^{6} \mathrm{BTA}, \mathrm{Cl}, \mathrm{H}^{8}$ and $\mathrm{H}_{2} \mathrm{O}$-molecule on coordination number of surface $\mathrm{Cu}$ atoms at adsorption site (parallel BTAH modes are calculated with the PBE-D' functional, while for all the others the $\mathrm{PBE}$ is used). Only the stablest identified adsorption energies at a given coordination number are reported [for BTAH, BTA, $\mathrm{Cl}$, and $\mathrm{H}$ see ref. 6 and 8 , whereas for $\mathrm{H}_{2} \mathrm{O}$ the points correspond to adsorption on (111), (100), (110), and adtetramer, adtrimer, and addimer defects on $\mathrm{Cu}(111)]$.

for the first three types several adsorption related properties are listed in Scheme 2 (the BTA-Cu adcomplexes are treated separately later).

3.2.1 Molecule-surface bond strength and role of surface geometry. Although the intact $\mathrm{BTAH}_{(\mathrm{ads})}$ bonds weakly and dissociated $\mathrm{BTA}_{(\mathrm{ads})}$ bonds strongly to copper surfaces, the $\mathrm{BTAH}_{(\mathrm{ads})} \rightarrow \mathrm{BTA}_{(\mathrm{ads})}+\mathrm{H}_{(\mathrm{ads})}$ dissociation is

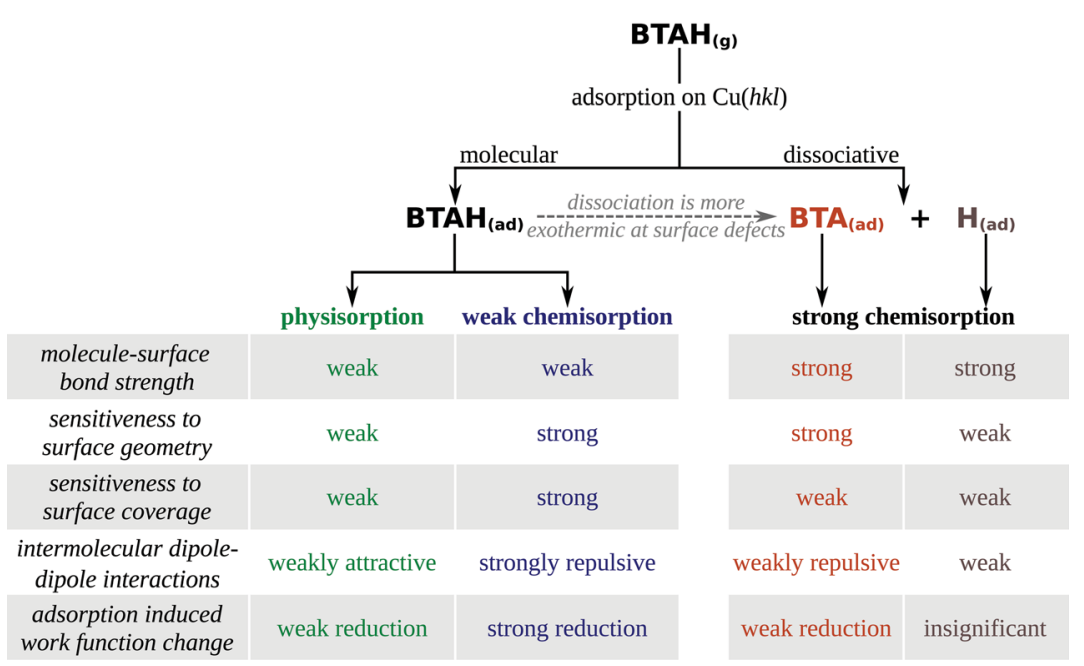

Scheme 2 Characteristics of molecular and dissociative adsorption of benzotriazole on copper surfaces. 
slightly endothermic on $\mathrm{Cu}(111)$ in the limit of zero coverage. The reason is the cost for the breakage of the N1-H bond; namely, the dissociation energy can be written as:

$$
\Delta E_{\mathrm{diss}}=E_{\mathrm{b}}^{\mathrm{BTA}{ }^{\odot}}+E_{\mathrm{b}}^{\mathrm{H}}-E_{\mathrm{b}}^{\mathrm{BTAH}}+D_{\mathrm{N} 1-\mathrm{H}},
$$

where $E_{\mathrm{b}}^{\mathrm{BTA}^{\odot}}, E_{\mathrm{b}}^{\mathrm{H}}$, and $E_{\mathrm{b}}^{\mathrm{BTAH}}$ are binding energies of respective species to copper surface; $D_{\mathrm{N} 1-\mathrm{H}}$ is the $\mathrm{N} 1-\mathrm{H}$ bond strength $(4.7 \mathrm{eV})$. For $\mathrm{Cu}(111)$ the respective numbers in the limit of zero-coverage are: $\Delta E_{\text {diss }}=-2.8+(-2.4)-(-0.6)+4.7$ $\mathrm{eV}=0.1 \mathrm{eV}$.

In order for dissociation to be exothermic, the following criterion has to be met (cf. eqn (2)):

$$
E_{\mathrm{b}}^{\mathrm{BTAH}}-E_{\mathrm{b}}^{\mathrm{BTA}^{\odot}}>E_{\mathrm{b}}^{\mathrm{H}}+D_{\mathrm{N} 1-\mathrm{H}} \cdot
$$

The bonding of $\mathrm{H}$ is rather insensitive to surface details and on $\mathrm{Cu}(h k l)$ the $E_{\mathrm{b}}^{\mathrm{H}}$ $\in[-2.4,-2.5] \mathrm{eV}$ (see Fig. 2). Hence the $\mathrm{BTA}_{(\text {ads })}$ has to bond by about $2.3 \mathrm{eV}$ stronger to the surface than $\mathrm{BTAH}_{(\mathrm{ads})}$ for dissociation to be exothermic. This criterion is met on open surfaces and low coordinated defects, because the enhancement of the molecule-surface bond strength is larger for $\mathrm{BTA}_{(\mathrm{ads})}$ than for $\mathrm{BTAH}_{(\mathrm{ads})}$ as the coordination number of surface $\mathrm{Cu}$ atoms involved in the adsorption site decreases (see Fig. 2); consequently dissociation energy becomes more exothermic in the same direction (Fig. 3).

In addition to $\mathrm{BTAH}_{(\mathrm{ads})}$, $\mathrm{BTA}_{(\mathrm{ads})}$, and $\mathrm{H}_{(\mathrm{ads})}$, Fig. 2 also plots the dependence of adsorption (binding) energy of $\mathrm{Cl}_{(\mathrm{ads})}$ and $\mathrm{H}_{2} \mathrm{O}_{(\mathrm{ads})}$ on the coordination number of surface $\mathrm{Cu}$ atoms involved in the adsorption site; the former may be seen as a prototype corrosive species and the latter is relevant due to the importance of water/metal interface for corrosion (though there is a large difference between a film of liquid water and a single water molecule).

3.2.2 Role of molecular dipole on lateral intermolecular interactions. Among the species considered in Fig. 2, the neutral BTAH displays by far the strongest

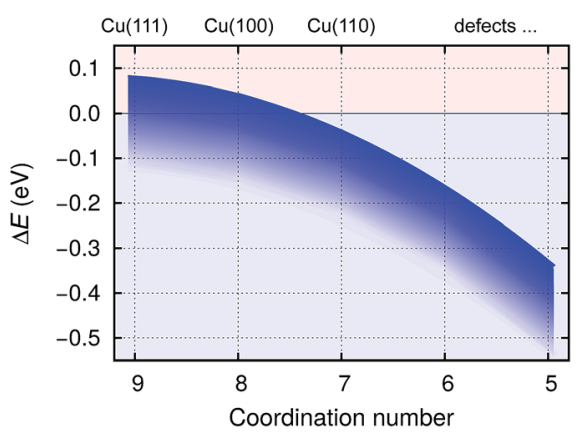

Fig. 3 Schematically shown dependence of benzotriazole dissociation energies for stand-alone $\mathrm{BTAH}_{\perp}\left(\mathrm{BTAH}_{\text {(ads) }} \rightarrow \mathrm{BTA}_{\text {(ads) }}+\mathrm{H}_{\text {ads, }}\right.$ cleavage of $\mathrm{N1}-\mathrm{H}$ bond) on coordination number of surface $\mathrm{Cu}$ atoms involved in the adsorption site; based on data of ref. 27. Dissociation energy $(\Delta E)$ is very sensitive to surface coverage due to a pronounced intermolecular long range repulsion between adsorbed $\mathrm{BTAH}_{\perp}$ (cf. Fig. 4). The dependence of $\Delta E$ on coverage is roughly indicated by the thickness of the blue band; the larger the coverage the more exothermic the $\Delta E$. 
dependence of adsorption energy on surface coverage. This dependence is due to a large permanent dipole moment of BTAH $(4.1 \mathrm{D})$, which results in repulsive and long range dipole-dipole interactions between perpendicularly adsorbed BTAH molecules, while for parallel physisorbed BTAH the lateral dipole-dipole interactions are far less important and slightly attractive at higher coverages (see Fig. 4). ${ }^{6,32}$ On the other hand, lateral dipole-dipole interactions are not that important for $\mathrm{BTA}_{(\mathrm{ads})}$ due to considerable adsorption induced charge transfer, which greatly reduces the dipole. ${ }^{7}$

Due to the strong lateral intermolecular repulsion between weakly chemisorbed $\mathrm{BTAH}_{(\mathrm{ads})}$ and much weaker lateral interactions for $\mathrm{BTA}_{(\mathrm{ads})}$ the dissociation of benzotriazole becomes more favorable as the surface coverage increases (this effect is indicated schematically by the width of the blue band in Fig. 3).

\subsubsection{Role of molecular dipole on adsorption induced work function change.}

In addition to long-range lateral intermolecular interactions, a large permanent molecular dipole can also lead to a significant adsorption induced dipole moment $(\mu)$, which alters the metal work function by $\Delta \Phi=-4 \pi \theta \mu$ (in atomic units), where $\theta$ is the surface coverage (in molecule/bohr ${ }^{2}$ unit); a positive value of $\mu$ stands for an outward-pointing dipole with the negative end at the surface and the positive end pointing outward (i.e., $\boldsymbol{\mu}=\boldsymbol{\mu} \cdot \boldsymbol{n}$, where $\boldsymbol{n}$ is the surface normal and $\boldsymbol{\mu}$ is the dipole of adsorbed molecule). The adsorption induced dipole moment due to a weakly chemisorbed $\mathrm{BTAH}_{\perp}$ is remarkably large (Table 1). Fig. 5 illustrates the dependence of $\Delta \Phi$ of $\mathrm{Cu}(111)$ on the molecular coverage for various forms of adsorbed benzotriazole. Even at rather small molecular coverage the reduction in the work function is appreciable for $\mathrm{BTAH}_{\perp}$. Also the $[\mathrm{BTA}-\mathrm{Cu}]_{n}$ and $[\mathrm{BTA}-\mathrm{Cu}-\mathrm{BTA}]$ organometallic complexes significantly affect the work function, whereas stand-

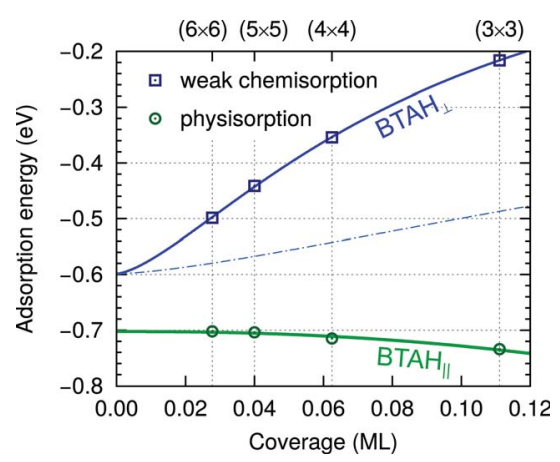

Fig. 4 Dependence of adsorption energy on the coverage for stand-alone weakly chemisorbed (blue squares) and physisorbed (green circles) BTAH on Cu(111); adsorption energies are taken from ref. 6 . The ML unit is defined as the number of molecules per surface $\mathrm{Cu}$ atom. Curves and zero-coverage adsorption energies are obtained with a polarizable point-dipole model extrapolation of ref. 32. The dependence is plotted up to a coverage of $0.12 \mathrm{ML}$, where the physisorbed $\mathrm{BTAH}_{\|}$reaches optimum; ${ }^{23}$ at larger coverage the molecules start to feel intermolecular Pauli repulsion. At the water/solid interface the long range lateral intermolecular interactions would be screened by the solvent molecules; the effect is roughly estimated by a thin dash-dotted blue line, which approximates the lateral dependence for the permittivity of $\varepsilon=6$, which is a typical value for water in the double-layer ${ }^{33}$ (note that continuum dielectric approximation is not expected to be valid at short intermolecular distances and also the magnitude of adsorption energy would be significantly altered by solvent effects). 
Table 1 Adsorption induced dipole moments $(\mu)$ and work function changes $(\Delta \Phi)$ on

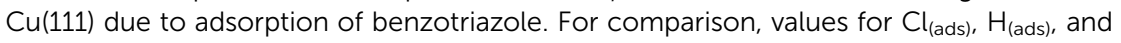
adsorbed $\mathrm{H}_{2} \mathrm{O}$-molecule are also listed

\begin{tabular}{|c|c|c|c|c|c|}
\hline Species & Adsorption mode & Shown in & Coverage (ML) & $\mu(\mathrm{D})$ & $\Delta \Phi(\mathrm{eV})$ \\
\hline \multirow[t]{2}{*}{$\mathrm{BTAH}_{\perp}$} & $\mathrm{N} 2+\mathrm{N} 3^{a}$ & Fig. 1a & $1 / 9$ & 3.15 & -2.25 \\
\hline & & & $1 / 16$ & 4.72 & -1.90 \\
\hline \multirow{2}{*}{$\mathrm{BTAH}_{\|}$} & stand-alone & Fig. 1c & $1 / 9$ & 0.84 & -0.62 \\
\hline & H-network & Fig. 1d & $1 / 10$ & 0.96 & -0.64 \\
\hline $\mathrm{BTA}_{(\mathrm{ads})}$ & $\mathrm{N} 2+\mathrm{N} 3^{a}$ & Fig. 1e & $1 / 16$ & 0.51 & -0.21 \\
\hline \multirow[t]{2}{*}[\mathrm{BTA}-\mathrm{Cu}]{$_{n}$} & $\mathrm{~N} 1+\mathrm{N} 2+\mathrm{N} 3^{a}$ & Fig. $1 \mathrm{i}$ & $2 / 23$ & 1.91 & -1.07 \\
\hline & & & $1 / 5$ & 1.18 & -1.52 \\
\hline $\mathrm{Cl}_{(\mathrm{ads})}$ & fcc & - & $1 / 9$ & -0.34 & +0.24 \\
\hline $\mathrm{H}_{(\mathrm{ads})}$ & fcc & - & $1 / 4$ & -0.03 & +0.04 \\
\hline $\mathrm{H}_{2} \mathrm{O}_{\mathrm{gds}}$ & top & - & $1 / 9$ & +0.68 & -0.49 \\
\hline
\end{tabular}

${ }^{a}$ Notation indicates which $\mathrm{N}$ atoms bond to $\mathrm{Cu}$. The $\mathrm{N} 1$ and $\mathrm{N} 3$ atoms are symmetry equivalent for BTA.

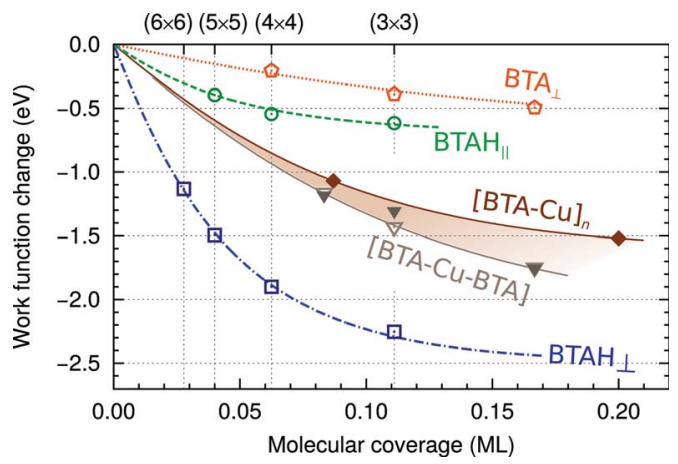

Fig. 5 Dependence of $\Delta \Phi$ of $\mathrm{Cu}(111)$ on the molecular coverage for various forms of adsorbed benzotriazole. The curves are drawn by fitting the data points with the polarizable point-dipole model of ref. 32. For organometallic complexes the dependence is emphasized by the brownish band.

alone-BTA $(\mathrm{ads}), \mathrm{Cl}_{(\mathrm{ads})}$, and $\mathrm{H}_{(\mathrm{ads})}$ do not (Table 1). Altered work functions affect the adsorption of ions and this issue is discussed in Section 3.3.1.

In this respect it should be noted that a large permanent molecular dipole of the inhibitor molecule does not automatically lead to a reduction in the work function. It depends on the adsorption structure of the inhibitor and for a weakly chemisorbed BTAH on copper, the adsorption structure is such that this is true.

\subsection{Adsorption at water/metal interfaces}

In the earlier discussion the adsorption of benzotriazole was considered at vacuum/copper interfaces, but in the context of corrosion inhibition the water/ metal interface is more relevant. The presence of aqueous solvent considerably affects the energetics of adsorption due to an interplay of several competitive effects, i.e., molecule-metal, molecule-water, and metal-water interactions. In 
order to understand these effects, the presence of water has to be either implicitly or explicitly considered in calculations. The explicit modeling is, however, rather tedious. For this reason, the involved effects have been only roughly estimated ${ }^{7,8}$ by following an approach that utilizes a thermodynamic cycle, ${ }^{34}$ which is shown in Scheme 3. The adsorption energy of deprotonated $\mathrm{BTA}^{-}$or any other anion from the solution $\left(\mathrm{A}_{(\text {solv })}^{-} \rightarrow \mathrm{A}_{(\text {ads })}+\mathrm{e}_{\text {metal }}^{-}\right)$can be written as: $t$

$$
\Delta G_{\mathrm{ads}}^{(\mathrm{aq})} \approx\left(E_{\mathrm{b}}^{\odot}-\Delta G_{\mathrm{solv}}^{\mathrm{A}^{-}}\right)+\left(\mathrm{EA}^{\odot}-\Phi^{*}\right)+\Delta \Delta G_{\mathrm{solv}}^{\mathrm{A} \| \text { metal }},
$$

where:

$$
\Delta \Delta G_{\mathrm{solv}}^{\mathrm{A} \| \text { metal }}=\Delta G_{\mathrm{solv}}^{\mathrm{A} \text { |metal }}-\Delta G_{\text {solv }}^{\text {metal }}
$$

and $\Phi^{*}$ is the work function of the metal/water/vacuum system, which can be written as:

$$
\Phi^{*}=\Phi+\Delta \Phi,
$$

where $\Phi$ is the metal work function and $\Delta \Phi$ is its variation due to a thick layer of liquid water. ${ }^{35}$ For the meaning of other terms, refer to Scheme 3 . The terms were deliberately grouped in parentheses in eqn (4) to illustrate the competitive effects. The first grouped terms represent the competition for the molecule between the metal surface and the solvent. The second grouped terms represent the competition for the electron between the molecule and the metal surface. Each of these four terms is large in magnitude for anions such as $\mathrm{BTA}^{-}$and $\mathrm{Cl}^{-}$(e.g., a few to several $\mathrm{eV}$ ), whereas the last term in eqn (4) is expected to be small in magnitude for copper surfaces (well below $1 \mathrm{eV}$ ). ${ }^{7,8,36}$

For the adsorption of neutral species $\left(\mathrm{A}_{(\text {solv })} \rightarrow \mathrm{A}_{(\mathrm{ads})}\right)$ the corresponding eqn is simpler, because there are no electron terms. Hence:

$$
\Delta G_{\mathrm{ads}}^{(\mathrm{aq})} \approx\left(E_{\mathrm{b}}-\Delta G_{\mathrm{solv}}^{\mathrm{A}}\right)+\Delta \Delta G_{\mathrm{solv}}^{\mathrm{A} \| \text { metal }}
$$

In this case the $E_{\mathrm{b}}$ and $\Delta G_{\text {solv }}^{\mathrm{A}}$ of BTAH are much smaller in magnitude than the corresponding terms for deprotonated $\mathrm{BTA}^{-}$(or any other anion).

A large mutual cancellation between the competitive terms in eqn (4) and (7) results in moderate adsorption energies. As a consequence the huge difference between the gas-phase adsorption energies of $\mathrm{BTAH}_{(\mathrm{ads})}$ and $\mathrm{BTA}_{(\mathrm{ads})}$ is greatly reduced in aqueous-phase. Solvent effects also relatively favor the adsorption of $\mathrm{BTA}^{-}$compared to $\mathrm{Cl}^{-}$, because $\mathrm{Cl}^{-}$is much smaller than $\mathrm{BTA}^{-}$and solvates by about $0.6 \mathrm{eV}$ stronger; $\mathrm{Cl}$ also displays by $\approx 0.15 \mathrm{eV}$ larger electron affinity than $\mathrm{BTA}^{\odot}$. While in gas-phase $\mathrm{Cl}$ adsorbs stronger than $\mathrm{BTA}_{(\text {ads }}$ (see Fig. 2), the two just mentioned effects seem to reverse the adsorption energy trend and $\mathrm{BTA}_{(\mathrm{ads})}$ wins over $\mathrm{Cl}_{(\text {ads) }}$ in aqueous-phase. ${ }^{8}$

Solvent effects also diminish the adsorption energy dependence on the coordination of surface metal atoms because the adsorbate has to displace water molecule(s) from the surface during specific adsorption and water displays a

\footnotetext{
\# Eqn (4) is a straight blend of energy contribution $\left(E_{\mathrm{b}}^{\circ}\right)$ and solvation free energy terms; neither the zero-point energy correction nor the concentration (translational) and roto-vibrational entropy contributions to free energy are taken into account. The equation is therefore very approximate, but it should suffice to illustrate the discussed points.
} 


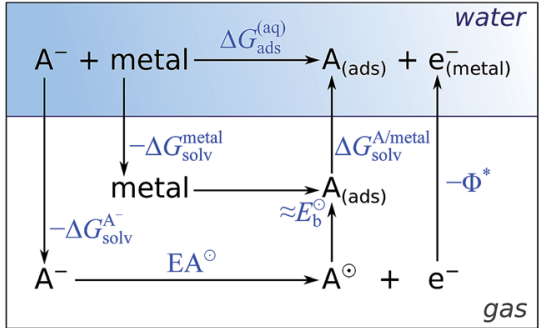

$$
\begin{aligned}
\mathrm{EA}^{\odot} & \equiv \text { electron affinity of } \mathrm{A}^{\odot} \\
\Phi^{*} & \equiv \text { metal/water/vacuum work function } \\
\Delta G_{\mathrm{solv}} & \equiv \text { solvation free energy } \\
E_{\mathrm{b}} & \equiv \mathrm{A} \text {-surface binding energy (measured wrt } \mathrm{A}_{(\mathrm{g})}^{\odot} \text { ) }
\end{aligned}
$$

Scheme 3 Thermodynamic cycle used to obtain a rough estimate for the adsorption energy of deprotonated molecule (or anion) in the aqueous phase (mnemonic: A stands for adsorbate or anion).

similar bonding enhancement trend as benzotriazole and $\mathrm{Cl}_{(\mathrm{ads})}$ (Fig. 2). This effect is captured by the $\Delta \Delta G_{\text {solv }}^{\mathrm{A} \| \text { metal }}$ term in eqn (4) and (7). For anionic species $\left(\mathrm{BTA}^{-}\right.$and $\mathrm{Cl}^{-}$) there is an additional effect that is even more pronounced and is due to dependence of $\Phi^{*}$ on the surface geometry. Namely, the reduction of $\Phi^{*}$ on going from (111) to (110) is so large $\$$ that it reverses the adsorption trend, i.e., estimated magnitudes of aqueous-phase adsorption energies of $\mathrm{BTA}^{-}$and $\mathrm{Cl}^{-}$ follow the $(111) \gtrsim(100)>(110)$ sequence. ${ }^{8}$ This finding is in agreement with the analysis of electrochemical experiments of Trasatti et al., ${ }^{38,39}$ who reported the same crystal-face specificity trend for the adsorption of halide anions on Ag.

3.3.1 Role of inhibitor induced work function change. Weakly chemisorbed BTAH considerably reduces the work function (Table 1). Such a pronounced effect on the work function should, according to eqn (4), drastically affect the

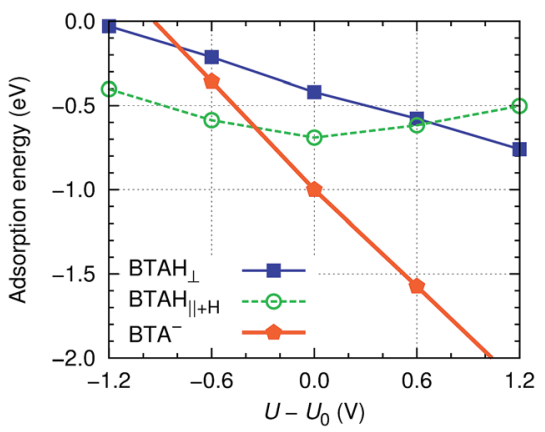

Fig. 6 Roughly estimated dependence of adsorption energy of benzotriazole on copper surfaces (i.e., values are averaged as $\left.\approx \frac{1}{3}[\mathrm{Cu}(111)+\mathrm{Cu}(100)+\mathrm{Cu}(110)]\right)$ on the electrode potential relative to static potential of zero charge, $U_{0} . \uparrow$ The following species are considered: weakly chemisorbed $\mathrm{BTAH}$ (labeled as $\mathrm{BTAH}_{\perp}$, left structure shown in Fig. 1a), physisorbed BTAH intermolecularly associated into a $\mathrm{H}$-bonded network $\left(\mathrm{BTAH}_{\|+\mathrm{H}}\right.$, Fig. 1d), and deprotonated $\mathrm{BTA}^{-}$(Fig. 1e).

$\S$ Both $\Phi$ and $\Delta \Phi[c f$. eqn (6)] reduce with reducing the coordination of surface Cu atoms; the PBE calculated $\Phi$ values are 4.84, 4.60, and $4.39 \mathrm{eV}$ for $\mathrm{Cu}(111), \mathrm{Cu}(100)$, and $\mathrm{Cu}(110)$, respectively, ${ }^{37}$ while the experimentally estimated $\Delta \Phi$ at potentials of zero charge are $-0.54,-0.57$, and $-0.65 \mathrm{eV}$, respectively, ${ }^{38}$ which result in $\Phi^{*}$ values of $4.29,4.03$, and $3.74 \mathrm{eV}$ for (111), (100), and (110) faces, respectively. ${ }^{8}$ 
adsorption of anions. On this basis one can argue that reduced work function should diminish any reaction that donates electron(s) to the metal, such as the adsorption of corrosive chloride anions $\left(\mathrm{Cl}_{(\text {solv })}^{-} \rightarrow \mathrm{Cl}_{(\mathrm{ads})}+\mathrm{e}_{(\text {metal })}^{-}\right)$, dissolution of $\operatorname{metal}\left(\right.$ e.g., $\left.\mathrm{Cu}_{\text {(solid) }} \rightarrow \mathrm{Cu}_{(\text {solv })}^{n+}+n \mathrm{e}_{(\text {metal })}^{-}\right)$, or oxidation of metal $\left(e . g ., 2 \mathrm{Cu}+\mathrm{H}_{2} \mathrm{O} \rightarrow\right.$ $\left.\mathrm{Cu}_{2} \mathrm{O}+2 \mathrm{H}^{+}+2 \mathrm{e}^{-}\right)$.

By comparing Fig. 4 and 5, it can be seen that the effect of the molecular dipole on the work function is larger than on the adsorption energy. The effect of the molecular dipole on the inhibitor-surface bonding has often been discussed in studies that correlate inhibitor electronic parameters with their inhibition efficiency, but the effect on the work function has not been appreciated.

3.3.2 Electric field effects in the double-layer. The electric field $(\boldsymbol{E})$ in the double-layer influences the adsorption due to several effects, which according to the current model can be decomposed into: (i) variation of the molecule-surface bonding, (ii) variation of contribution due to electron transfer from anion to electrode (or to cation from electrode), and (iii) variation of the $\Delta \Delta G_{\mathrm{solv}}^{\mathrm{A} \| \text { metal }}$ term. These effects were roughly estimated in ref. 7 and here this method is utilized to discuss the effect of electrode potential on various adsorbed forms of benzotriazole. In particular, Fig. 6 plots the estimated dependence of the aqueousphase adsorption energy on the electrode potential for the weakly chemisorbed BTAH (labeled as BTAH $_{\perp}$ ), physisorbed BTAH intermolecularly associated into H-bonding network $\left(\mathrm{BTAH}_{\|+\mathrm{H}}\right)$, and deprotonated $\mathrm{BTA}^{-}$.

This figure should be understood only qualitatively, because the presented adsorption energies are subjected to significant uncertainty due to the nature of involved approximations. Nevertheless, the qualitative trends (i.e., the slopes/ shapes of the curves) should be correctly captured. There are a few things to notice from the figure: (i) $\mathrm{BTAH}_{\|+\mathrm{H}}$ displays the well known parabolic dependence of simple organic molecules, with the strongest adsorption at the potential of zero charge..$^{33}$ (ii) The adsorption energy of $\mathrm{BTAH}_{\perp}$ becomes more exothermic as the

I The effects (i) and (ii) were estimated by putting the slab model (either adsorbate/copper or waterfilm/copper) in homogeneous electric field $\boldsymbol{E}$ and performing relaxation calculations at several different values of electric field. The relation between the electric field and electrode potential $(U)$ was treated within the Helmholtz-Perrin parallel plate capacitor model of double layer, i.e.:

$$
U=U_{0}+d \boldsymbol{n} \cdot \boldsymbol{E}
$$

where $U_{0}$ is the electrode potential corresponding to $\boldsymbol{E}=0$, which can be seen as a static potential of zero charge (spzc), but notice that spzc can be different from the measurable potential of zero charge. ${ }^{40}$ The proportionality constant $d$ is the thickness of a double layer, which was approximated by the often used value of $d=3 \AA^{41-43}$ The adsorption energies were then calculated as:

$$
\Delta G_{\mathrm{ads}}^{(\mathrm{aq})}(\boldsymbol{E})=\Delta G_{\mathrm{ads}}^{\mathrm{aq})}(0)+\delta E_{\mathrm{b}}^{\odot}(\boldsymbol{E})+\delta \Delta \Delta G_{\mathrm{solv}}^{\mathrm{A} \| \operatorname{metal}}(\boldsymbol{E})+z e\left(U-U_{0}\right),
$$

and

$$
\begin{gathered}
\delta E_{\mathrm{b}}^{\odot}(\boldsymbol{E})=E_{\mathrm{b}}^{\odot}(\boldsymbol{E})-E_{\mathrm{b}}^{\odot}(0), \\
\delta \Delta \Delta G_{\text {solv }}^{\mathrm{A} \| \operatorname{metal}}(\boldsymbol{E})=\Delta \Delta G_{\text {solv }}^{\mathrm{A} \| \operatorname{metal}}(\boldsymbol{E})-\Delta \Delta G_{\text {solv }}^{\mathrm{A} \| \operatorname{metal}}(0),
\end{gathered}
$$

where $e$ is the unit charge and $z$ is the charge of species in solution $\left(-1\right.$ for $\mathrm{BTA}^{-}$and 0 for BTAH). For more details see the ESI of ref. 7 . 
electrode potential becomes more positive (almost linearly). This distinctive behavior can be attributed to the orientation of molecular dipole of the two forms because the variation of molecule-surface bond with electric field is roughly proportional to $-\boldsymbol{\mu} \cdot \boldsymbol{E}$; for physisorbed BTAH the dipole points largely parallel to the surface, hence $-\boldsymbol{\mu} \cdot \boldsymbol{E} \approx 0$ and the parabolic dependence stems from the enhancement of water-metal interaction with increasing $\boldsymbol{E}$. On the other hand, the dipole of $\mathrm{BTAH}_{\perp}$ points outward and in this case $\partial E_{\mathrm{b}} / \partial U \approx \mu / d=0.3 e$ (if $d=$ $3 \AA$ and $\mu$ is taken from Table 1). $\|$ (iii) Finally, the slope of the BTA ${ }^{-}$line is largely dominated by the $-e\left(U-U_{0}\right)$ term, eqn (9), and is thus close to one.

According to Fig. 6, the $\mathrm{BTAH}_{\|+\mathrm{H}}$ form is the stablest among the three forms at low values of potential $\left(U-U_{0} \lesssim-0.3 \mathrm{~V}\right)$, but at larger values the deprotonated form becomes the stablest. The curves in Fig. 6 correspond to the following reactions:

$$
\begin{aligned}
& \mathrm{BTAH}_{(\text {solv })} \rightarrow \mathrm{BTAH}_{(\mathrm{ads})} \text { and } \\
& \mathrm{BTA}_{(\text {solv })}^{-} \rightarrow \mathrm{BTA}_{(\text {ads })}+\mathrm{e}_{(\text {metal })}^{-},
\end{aligned}
$$

which implies that $\mathrm{BTAH}_{(\mathrm{ads})}$ and $\mathrm{BTA}_{(\mathrm{ads})}$ are treated as independent. This may not always be the case due to a dissociation reaction at the surface:

$$
\mathrm{BTAH}_{(\mathrm{ads})} \rightleftharpoons \mathrm{BTA}_{(\mathrm{ads})}+\mathrm{H}_{(\mathrm{ads})}
$$

Alternatively the $\mathrm{H} 1$ proton can be abstracted by a neighboring water molecule (which may then diffuse away from the surface):

$$
\mathrm{BTAH}_{(\mathrm{ads})} \rightleftharpoons \mathrm{BTA}_{(\mathrm{ads})}+\mathrm{H}^{+}+\mathrm{e}^{-} \text {. }
$$

The argument applies to both cases. Consider, for example, the desorption of $\mathrm{BTA}_{(\mathrm{ads})}$ under low $\mathrm{pH}$ conditions. ${ }^{* *}$ If the barrier for the reverse of reaction (12) or (13) is not too large, it may be more convenient for $\mathrm{BTA}_{(\mathrm{ads})}$ to desorb as $\mathrm{BTAH}_{(\mathrm{ads})}$; namely, the larger is the coverage of $\mathrm{H}_{(\mathrm{ads})}$ (or concentration of $\mathrm{H}^{+}$) the more to the left the reaction (12) [or (13)] is pushed. This argument, together with Fig. 6, suggests that $\mathrm{BTA}_{(\mathrm{ads})}$ is more relevant at higher potentials and higher $\mathrm{pH}$, while $\mathrm{BTAH}_{(\mathrm{ads})}$ may dominate at low potentials and low $\mathrm{pH}$ (relatively speaking); this is in fact self-evident from reaction (13). With respect to corrosion inhibition, it would be desirable to make reaction (12) irreversible or at least to push the dissociation reaction to the right as much as possible, because $\mathrm{BTA}_{(\text {ads })}$ bonds much stronger to the surface than $\mathrm{BTAH}_{(\mathrm{ads})}$ and strong bonds imply larger desorption barriers than weak bonds. This may be the case on low coordinated surface defects, because Fig. 3 reveals that dissociation is more exothermic there. A step further in this direction is achieved by the BTA-Cu organometallic complexation, which is an issue that we turn to now.

\footnotetext{
$\|$ This implies that $E_{\mathrm{b}}$ changes by $\approx 0.3 \mathrm{eV}$ if potential is altered by $1 \mathrm{~V}$. The actual calculations reveal that the variation is even larger due to molecular polarization, but this extra effect is largely cancelled by the enhancement of the water-metal interaction with increasing $\boldsymbol{E}$ (note that water has a considerably smaller dipole moment than BTAH); hence the slope of the $\mathrm{BTAH}_{\perp}$ line in Fig. 6 is close to 0.3e.

** Although the argument is similar for both reactions, (12) and (13), the atomistic mechanism is different. In the reverse direction of reaction (12) $\mathrm{BTA}_{(\mathrm{ads})}$ reacts with $\mathrm{H}_{(\mathrm{ads})}$ (Langmuir-Hinshelwood mechanism), while in the reverse of reaction (13) the $\mathrm{H}^{+}$comes from solution and reacts with $\mathrm{BTA}_{(\mathrm{ads})}$ directly (Eley-Rideal mechanism).
} 


\subsection{Role of BTA-Cu organometallic complexes}

The ability of benzotriazole to inhibit corrosion is often attributed to formation of protective BTA-Cu surface complexes. $\dagger \uparrow$ The arguments presented earlier may provide a sound rationale of why this is so. According to DFT calculations, ${ }^{7,8}$ the BTA-Cu organometallic complexes are thermodynamically more stable than standalone chemisorbed $\mathrm{BTA}_{(\mathrm{ads})}$. For example, the two organometallic complexesshown in Fig. $1 \mathrm{~h}$ and $\mathrm{i}$-are by about 0.1 to $0.2 \mathrm{eV}$ per BTA more stable than the stand-alone form. This difference is not large, but it includes the cost for the $\mathrm{Cu}$ adatoms formation $[0.76 \mathrm{eV}$ per atom on $\mathrm{Cu}(111)]$ that are incorporated into the complex (for more details, see ref. 8). This implies that the gross bonding of BTA within the organometallic complex is much stronger than the BTA-surface bond of the stand-alone form. Moreover, within the complex all the BTA's N atoms are bonded to $\mathrm{Cu}$ atoms and are thus saturated ( $c f$. Fig. $1 \mathrm{~h}$ and i). Hence, the removal of BTA or the fusion of $\mathrm{H}$ into the BTA are more unlikely for the complex than for the stand-alone form. The organometallic complexes are therefore more resistant than the stand-alone $\mathrm{BTA}_{(\mathrm{ads})}$ forms in the reverse of reaction (12) or (13), which eventually lead to desorption of benzotriazole. But they are still susceptible to potential and $\mathrm{pH}$, according to the reaction of Youda: ${ }^{47} n \mathrm{BTAH}_{(\mathrm{ads})}+n \mathrm{Cu} \rightleftharpoons[\mathrm{Cu}-\mathrm{BTA}]_{n}+n \mathrm{H}^{+}+n \mathrm{e}^{-}$.

According to some researchers the formation of protective BTA-Cu complex is faster on bare metallic surfaces, ${ }^{16}$ while others emphasized the importance of surface oxides in their formation. ${ }^{\mathbf{1 4 , 4 6}}$ The latter is one amongst other reasons that the adsorption of benzotriazole on oxidized copper surfaces is considered below.

\section{Adsorption of benzotriazole on oxidized copper surfaces}

Up to this point the bonding of benzotriazole with reduced (oxide-free) copper surfaces was considered, which are more relevant at acidic $\mathrm{pH}$, but in other conditions the copper surfaces are oxidized. It should be noted that bare metallic surfaces are structurally and electronically simpler than oxidized surfaces, which is the reason that the bonding of benzotriazole to oxidized copper surfaces has been considered by DFT calculations to a sufficiently smaller extent than to bare copper surfaces. Jiang and Adams ${ }^{48}$ studied the bonding of BTAH on stoichiometric $\mathrm{Cu}_{2} \mathrm{O}(111)$, while Peljhan and Kokalj ${ }^{49,50}$ extended the calculations and considered also the bonding on thermodynamically stablest so-called $\mathrm{Cu}_{2} \mathrm{O}(111)$ w/o- $\mathrm{Cu}^{\mathrm{CUS}}$ and $\mathrm{Cu}_{2} \mathrm{O}(110)$ : CuO. Currently, the adsorption of benzotriazole is considered in more detail on a broader set of potential surface sites on oxidized copper surfaces.

Because oxidized surfaces may display a plethora of different structures and stoichiometries, some of which might be rather complicated, a reductionistic approach is followed. The surfaces of $\mathrm{Cu}_{2} \mathrm{O}$ are well characterized in gas-phase and these are taken as a starting model of oxidized copper surface (Section 4.1).

\footnotetext{
$\dagger \dagger$ Linear polymeric structure consisting of alternating $\mathrm{Cu}^{+}$and $\mathrm{BTA}^{-}$ions in $1: 1$ ratio that form a -Cu-BTA-Cu-BTA- bidentate structure is usually proposed;,10,44-46 a corresponding model of such $[\mathrm{BTA}-\mathrm{Cu}]_{n}$ adstructure on bare copper surface, as obtained by DFT calculations, is shown in (Fig. 1i). ${ }^{7}$ Recently, Chen and Häkkinen proposed, on the basis of DFT calculations, a [BTA-Cu-BTA] dimer adstructure (Fig. 1h). ${ }^{25}$ This adcomplex was recently observed experimentally by STM (scanning tunneling microscopy) under ultra-high-vacuum conditions on $\mathrm{Cu}(111) .^{28,31}$
} 
Subsequently also simple models of hydroxylated $\mathrm{Cu}_{2} \mathrm{O}$ surface are considered (Section 4.2), because several studies indicate that surface oxide layer is likely hydroxylated in aqueous solution. ${ }^{51-54}$ Due to obvious modeling reasons, the reported results again refer to the solid/vacuum interface and all the models are based on cuprous oxide [the $\mathrm{Cu}$ (II) oxidation state is not considered]. In this respect it should be noted that the $\mathrm{Cu}_{2} \mathrm{O}$ is more relevant than $\mathrm{CuO}$ for formation of the protective film of benzotriazole. ${ }^{13}$

\section{1 $\mathrm{Cu}_{2} \mathrm{O}$ as a model of oxidized copper surfaces}

4.1.1 Stability of various $\mathrm{Cu}_{2} \mathrm{O}$ surfaces. The stability of various $\mathrm{Cu}_{2} \mathrm{O}$ surfaces in an ambient oxygen atmosphere was characterized in detail by Soon et al., by means of DFT calculations. ${ }^{55,56}$ Two surfaces display notably lower surface free energies than the others; one of them is the $\mathrm{Cu}_{2} \mathrm{O}(111)-\mathrm{w} / \mathrm{o}-\mathrm{Cu}^{\mathrm{CUS}}$ (Fig. 7c). It differs from stoichiometric $\mathrm{Cu}_{2} \mathrm{O}(111)$ (Fig. 7a and b) by the absence of coordinately unsaturated (CUS) copper atoms; the label " $\mathrm{Cu}_{2} \mathrm{O}(111)-\mathrm{w} / \mathrm{o}-\mathrm{Cu}$ CUs", thus stands for $\mathrm{Cu}_{2} \mathrm{O}(111)$ without $\mathrm{Cu}$ CUS atoms. The STM study of Önsten et al., ${ }^{57}$ seems to have identified the $\mathrm{Cu}_{2} \mathrm{O}(111)-\mathrm{w} / \mathrm{o}-\mathrm{Cu}{ }^{\mathrm{CUS}}$ structure (their proposed model B). According to their nomenclature this surface was labeled as
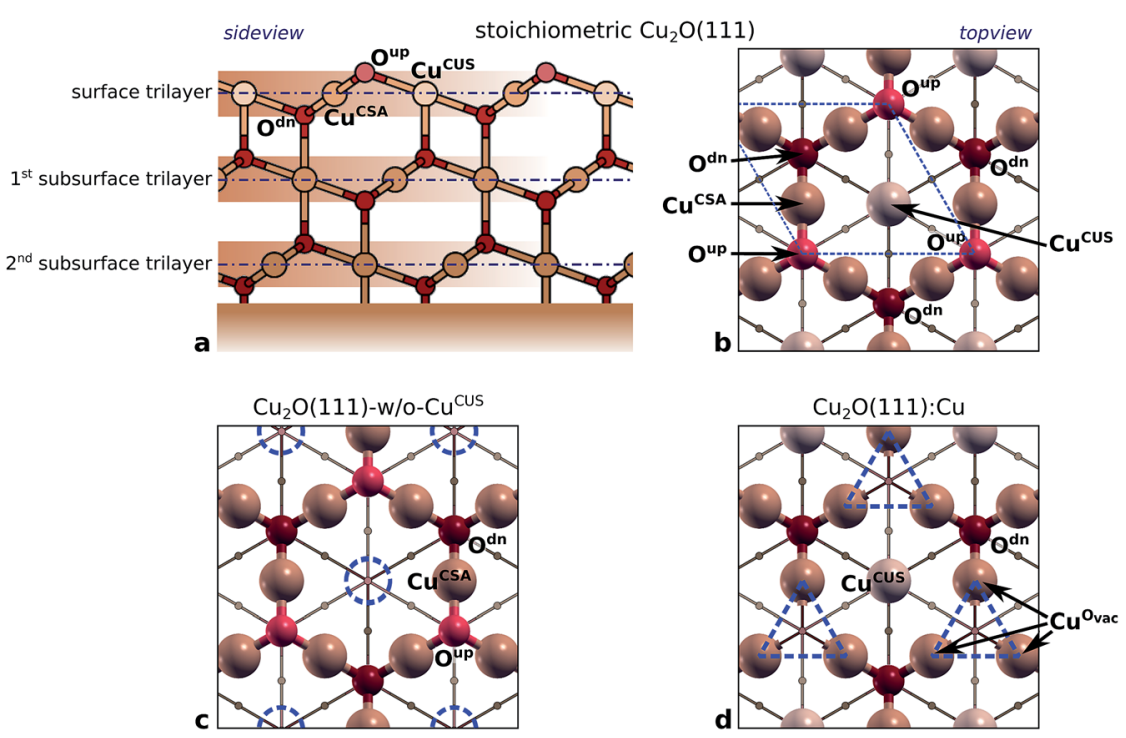

Fig. 7 Structures of various considered $\mathrm{Cu}_{2} \mathrm{O}$ surfaces (copper and oxygen atoms are colored brownish and reddish, respectively). For clarity of presentation non-relaxed (nonreconstructed) structures are plotted and surface trilayers are emphasized in the top-view plots. ( $\mathrm{a}$ and b) Side- and top-view of stoichiometric $\mathrm{Cu}_{2} \mathrm{O}(111)$; note the stacking of $\mathrm{O}-\mathrm{Cu}-\mathrm{O}$ trilayers shown in the side view. There are six atoms in the surface trilayer per $(1 \times 1)$-unit cell [indicated by blue dashed parallelogram in (b)]: $3 \times \mathrm{Cu}^{\mathrm{CSA}}, 1 \times \mathrm{Cu}^{\mathrm{CUS}}$, $1 \times \mathrm{O}^{\text {up }}$, and $1 \times \mathrm{O}^{\text {dn }}$ (note that $\mathrm{O}^{\mathrm{dn}}$ is CSA and Oup is CUS). (c) Non-stoichiometric $\mathrm{Cu}_{2} \mathrm{O}(111)$ without $\mathrm{Cu}^{\text {cus }}$ atoms (labeled as $\mathrm{Cu}_{2} \mathrm{O}(111)-$ w/o- $\mathrm{Cu}{ }^{\mathrm{CUS}}$ ); $\mathrm{Cu}^{\mathrm{CUS}}$ vacancies are indicated by blue dashed circles. (d) $\mathrm{Cu}$ terminated $\mathrm{Cu}_{2} \mathrm{O}(111)$ surface (labeled as $\mathrm{Cu}_{2} \mathrm{O}(111)$ : $\mathrm{Cu}$ ), which can be seen as stoichiometric $\mathrm{Cu}_{2} \mathrm{O}(111)$ without $\mathrm{O}^{\text {up }}$ atoms; $\mathrm{O}^{\text {up }}$ vacancies are indicated by blue dashed triangles and the surrounding $\mathrm{Cu}$ atoms are labeled as $\mathrm{Cu}^{\mathrm{O} \text { vac }}$ (note that $\mathrm{Cu}^{\text {vac }}$ is CUS). 
$(1 \times 1)$. In addition, they also observed the $(\sqrt{3} \times \sqrt{3}) \mathrm{R} 30^{\circ}$ reconstructed surface, where one third of surface oxygens ( $\mathrm{O}^{\mathrm{up}}$ as defined in Fig. 7) are missing. A characteristic of the $(\sqrt{3} \times \sqrt{3}) \mathrm{R}^{\circ} 0^{\circ}$ is the presence of the $\mathrm{Cu}^{\mathrm{O}_{\text {vac }}}$ sites that are described below. Under electrochemical conditions the $\mathrm{Cu}_{2} \mathrm{O}(111)$ surface can be $\mathrm{Cu}$ terminated (labeled as $\mathrm{Cu}_{2} \mathrm{O}(111): \mathrm{Cu}$ ) and stabilized by adsorbed hydroxyls. ${ }^{51,52,58}$ Adsorption of benzotriazole on hydroxylated $\mathrm{Cu}_{2} \mathrm{O}(111)$ is considered in Section 4.2.

4.1.2 Description of considered adsorption sites. Fig. 7 shows the structure of stoichiometric $\mathrm{Cu}_{2} \mathrm{O}(111), \quad \mathrm{Cu}_{2} \mathrm{O}(111)-\mathrm{w} / \mathrm{o}-\mathrm{Cu}^{\mathrm{CUS}}$, and $\mathrm{Cu}$ terminated $\mathrm{Cu}_{2} \mathrm{O}(111): \mathrm{Cu}$. It also defines the naming of various atoms (ions) in the near surface region. Some atoms (ions) in the surface region are coordinatively saturated (CSA) and others are coordinatively unsaturated (CUS); caption of Fig. 7 explicitly lists all the CSA and CUS atoms. Note that the naming of atoms does not follow the coordinative CSA/CUS description (only the surface $\mathrm{Cu}$ atoms of stoichiometric $\mathrm{Cu}_{2} \mathrm{O}(111)$ are named $\mathrm{Cu}^{\mathrm{CUS}}$ and $\mathrm{Cu}^{\mathrm{CSA}}$ ), but a rather more structural-like description, e.g., $\mathrm{O}^{\text {up }}$ and $\mathrm{O}^{\mathrm{dn}}$ indicate that they are above and below the surface $\mathrm{Cu}$ layer, respectively. The $\mathrm{Cu}$ atoms, which surrounds the $\mathrm{O}^{\text {up }}$ vacancy (Fig. $7 \mathrm{~d}$ ) are CUS, but they are named $\mathrm{Cu}^{\mathrm{O}_{\text {vac }}}$ as to differentiate them from $\mathrm{Cu}^{\text {CUS }}$ of $\mathrm{Cu}_{2} \mathrm{O}(111)$.

Calculations on $\mathrm{Cu}_{2} \mathrm{O}(111)$ surfaces were performed with slabs that consist of four trilayers. A $(2 \times 2)$ supercell was used. Its size would correspond to $\mathrm{Cu}(111)-$ $(4 \times 4)$, but the lattice parameter of $\mathrm{Cu}_{2} \mathrm{O}$ bulk $(4.35 \AA$, PBE value) is larger than for $\mathrm{Cu}(3.67 \AA)$, hence it actually corresponds to the size of $\mathrm{Cu}(111)-(4.7 \times 4.7)$ supercell. Because of the coverage dependence of BTAH adsorption energies ( $c f$. Fig. 4), this should be kept in mind when comparing the results between oxidized and reduced copper surfaces. The $\mathrm{Cu}_{2} \mathrm{O}(111)-\mathrm{w} / \mathrm{o}-\mathrm{Cu}^{\mathrm{CUS}}$ was taken as a reference; the adsorption on the $\mathrm{Cu}^{\mathrm{CUS}}$ and $\mathrm{Cu}^{\mathrm{O}_{\text {vac }}}$ sites may be hence considered as adsorption on defect sites of $\mathrm{Cu}_{2} \mathrm{O}(111)$-w/o-Cu ${ }^{\text {CUs }}$. Two models-one based on $\mathrm{Cu}_{2} \mathrm{O}(111)$-w/o-Cu ${ }^{\text {Cus }}$ and the other on $\mathrm{Cu}_{2} \mathrm{O}(111)$ : $\mathrm{Cu}+$-were used for each defect so as to have an estimate of how susceptible the adsorption characteristics are on the specifics of the given model (the results were however not too different between different models). The results for adsorption of $\mathrm{BTAH}_{(\mathrm{ads})}$ and $\mathrm{BTA}_{(\mathrm{ads})}$ on various sites of $\mathrm{Cu}_{2} \mathrm{O}(111)$ are presented in Fig. 8 .

4.1.3 Bonding of BTAH to various sites of $\mathrm{Cu}_{2} \mathrm{O}(\mathbf{1 1 1})$. Optimized adsorption structures of $\mathrm{BTAH}_{(\mathrm{ads})}$ are shown in Fig. 8a-c. The trend of the molecule-surface bonding follows the order: $\mathrm{Cu}^{\mathrm{CSA}}<\mathrm{Cu}^{\mathrm{O}_{\text {vac }}}<\mathrm{Cu}^{\mathrm{CUS}}$. According to Fig. 8a, the

\$t The adsorption on $\mathrm{Cu}^{\mathrm{CUS}}$ and $\mathrm{Cu}^{\mathrm{O}_{\text {vac }}}$ sites of $\mathrm{Cu}_{2} \mathrm{O}(111)-\mathrm{w} / \mathrm{o}-\mathrm{Cu}^{\mathrm{CUS}}$ model was modeled by adding one $\mathrm{Cu}^{\text {CUS }}$ and removing one $\mathrm{O}^{\text {up }}$ ion per $(2 \times 2)$ supercell, whereas $\mathrm{Cu}_{2} \mathrm{O}(111): \mathrm{Cu}$ model already consists of both $\mathrm{Cu}^{\text {Cus }}$ and $\mathrm{Cu}^{\mathrm{O}_{\text {vac }}}$ sites. Note, however, that $\mathrm{Cu}_{2} \mathrm{O}(111): \mathrm{Cu}$ is a polar terminated surface of Tasker type- $3,{ }^{59}$ hence it undergoes a reconstruction. ${ }^{52}$ In particular, the $\mathrm{O}^{\mathrm{dn}}$ ions upshift to the plane of surface $\mathrm{Cu}$ ions, the three $\mathrm{Cu}^{\mathrm{O}_{\text {vac }}}$ ions (marked by blue dashed triangles in Fig. 7d) move closer to one another and

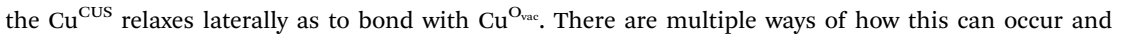
different reconstruction patterns display significantly different stability. For this reason the adsorption of benzotriazole on $\mathrm{Cu}_{2} \mathrm{O}(111)$ : $\mathrm{Cu}$ is modeled using the following procedure: (i) the structure of $\mathrm{Cu}_{2} \mathrm{O}(111): \mathrm{Cu}$ is optimized, (ii) benzotriazole is added to the structure-(i) and relaxation is performed, and (iii) benzotriazole is removed and the surface is reoptimized. The adsorption energy is then calculated by using the total energies of (ii) and (iii). The reason for step (iii) is that step (ii) lowers the symmetry of the system (i.e., the molecule perturbs the system) and the surface may find a new relaxation pattern with lower energy; step (iii) therefore assures that structures (ii) and (iii) have a compatible relaxation pattern. A more sophisticated (but computationally much more expensive) approach would be to use a simulated annealing technique as was described by Islam et al. ${ }^{52}$ 
bonding of BTAH to $\mathrm{Cu}^{\mathrm{CSA}}$ is thus similar to that of $\mathrm{Cu}(111)$ (keeping in mind that compatible coverages have to be compared), whereas on coordinatively unsaturated $\mathrm{Cu}^{\mathrm{O}_{\text {vac }}}$ and $\mathrm{Cu}^{\mathrm{CUS}}$ the bonding is considerably enhanced and it is even stronger than on low coordinated defects on bare $\mathrm{Cu}$ surfaces ( $c f$. Fig. 2). Indeed, the bonding to $\mathrm{Cu}^{\mathrm{CUS}}$ is so large that it overcompensates the thermodynamic deficiency of $\mathrm{Cu}^{\mathrm{CUS}}$ and, consequently, the BTAH@ $\mathrm{Cu}^{\mathrm{CUS}}$ is thermodynamically more stable than BTAH@Cu ${ }^{\mathrm{CSA}} . \S \S$

4.1.4 Bonding of BTA to various sites of $\mathrm{Cu}_{2} \mathrm{O}(\mathbf{1 1 1})$. Adsorption structures of $\mathrm{BTA}_{(\mathrm{ads})}$ are shown in Fig. $8 \mathrm{~d}-\mathrm{f}$. It is evident that on $\mathrm{Cu}_{2} \mathrm{O}$ surfaces the $\mathrm{BTA}_{(\mathrm{ads})}$ bonds considerably stronger than $\mathrm{BTAH}_{(\mathrm{ads})}$, but the difference is smaller than on bare $\mathrm{Cu}$ surfaces. The bonding is the weakest on $\mathrm{Cu}^{\mathrm{CSA}}$ sites, $-2.0 \mathrm{eV}$, while on $\mathrm{Cu}^{\mathrm{O}_{\text {vac }}}$ and $\mathrm{Cu}^{\text {CUS }}$ sites it is enhanced to -3.0 and $-2.8 \mathrm{eV}$, respectively.

4.1.5 Dissociation of BTAH on various sites of $\mathrm{Cu}_{2} \mathrm{O}$. According to eqn (3), the $\mathrm{BTA}_{(\mathrm{ads})}$ has to bond by about $2.3 \mathrm{eV}$ stronger to bare $\mathrm{Cu}$ surfaces than $\mathrm{BTAH}_{(\mathrm{ads})}$ in order for the dissociation to be exothermic. On $\mathrm{Cu}_{2} \mathrm{O}$ surfaces this difference is smaller $(1.7 \mathrm{eV})$, because $\mathrm{H}$ binds stronger to $\mathrm{Cu}_{2} \mathrm{O}(-3.0 \mathrm{eV})$ than to $\mathrm{Cu}$ surfaces. $\uparrow$ Nevertheless, the $E_{\mathrm{b}}^{\mathrm{BTAH}}-E_{\mathrm{b}}^{\mathrm{BTA}^{\circ}}>1.7 \mathrm{eV}$ condition is met only on $\mathrm{Cu}^{\mathrm{O}_{\text {vac }}}$ sites, which implies that dissociation of $\mathrm{BTA}_{(\mathrm{ads})}$ is thermodynamically favored only thereon (the issue is confirmed by separate $\mathrm{BTA}_{(\text {ads })}+\mathrm{H}_{(\text {ads })}$ coadsorption calculations). It should be noted, however, that under non-acidic conditions, the $\mathrm{BTA}^{-}$can also be supplied from solution; the BTAH's $\mathrm{p} K_{\mathrm{a}}$ constant at $25{ }^{\circ} \mathrm{C}$ is 8.4 for BTAH $\rightleftharpoons \mathrm{BTA}^{-}+\mathrm{H}^{+},{ }^{60}$ hence at $\mathrm{pH}=7$ the $\mathrm{BTA}_{(\text {solv })}^{-}: \mathrm{BTAH}_{(\text {solv })}$ ratio is $4: 96$.

4.1.6 BTA-Cu organometallic complexes on $\mathrm{Cu}_{2} \mathrm{O}$. The rationale behind the formation of $\mathrm{BTA}-\mathrm{Cu}$ organometallic complexes on bare $\mathrm{Cu}$ surfaces is the stronger bonding of $\mathrm{BTA}_{(\mathrm{ads})}$ to low coordinated $\mathrm{Cu}$ sites. ${ }^{8}$ It was shown above that benzotriazole also binds stronger to coordinatively unsaturated sites on $\mathrm{Cu}_{2} \mathrm{O}$ surfaces. For this reason the issue of BTA-Cu complexation on oxidized copper surfaces is considered from a DFT perspective. The aim is not to identify structures that actually exist-this seems insurmountable without any experimental input-but rather to investigate whether organometallic complexes of benzotriazole are favored over stand-alone $\mathrm{BTA}_{(\mathrm{ads})}$ on oxidized copper surfaces, which is affirmative according to experiments..$^{13,14,46,61}$ Several complexes were identified that are more stable than stand-alone adsorbed $\mathrm{BTA}_{(\mathrm{ads})}$ forms, and Fig. 9 shows exemplar monomer, dimer, and polymer adcomplex structures. Gross binding of BTA within the monomer, dimer, and polymer complexes is calculated to be -4.3 , -3.8 , and $-3.7 \mathrm{eV}$ per BTA, respectively. If the cost for the formation of $\mathrm{Cu}^{\mathrm{CUS}}$ and

$\S \S$ The BTAH bonding enhancement on passing from $\mathrm{Cu}^{\mathrm{CSA}}$ to $\mathrm{Cu}^{\mathrm{CUS}}$ is $1.1 \mathrm{eV}$, while the cost for the $\mathrm{Cu}^{\text {CUS }}$ formation is between 0.43 and $1.06 \mathrm{eV}$, taking into account the range of $\mathrm{Cu}$ chemical potential between that of $\mathrm{Cu}$ and $\mathrm{Cu}_{2} \mathrm{O}$ bulk, i.e., $\mu_{\mathrm{Cu}}^{\max }=E_{\mathrm{Cu}}^{\text {bulk }}$ and $\mu_{\mathrm{Cu}}^{\min }=\frac{1}{2}\left[E_{\mathrm{Cu}_{2} \mathrm{O}}^{\text {bulk }}-\frac{1}{2} E_{\mathrm{O}_{2}}\right]$, where $E_{\mathrm{Cu}}^{\text {bulk }}, E_{\mathrm{Cu}_{2} \mathrm{O}}^{\text {bulk }}$ and $E_{\mathrm{O}_{2}}$ are DFT total energies of $\mathrm{Cu}$ atom in the Cu-bulk, formula unit of $\mathrm{Cu}_{2} \mathrm{O}$ bulk, and oxygen molecule, respectively.

ฯ 9 Note that on $\mathrm{Cu}_{2} \mathrm{O}$ surfaces, $\mathrm{H}$ binds stronger to $\mathrm{O}$ than to $\mathrm{Cu}$ ion, hence the dissociation reaction should be correspondingly written as:

$$
\mathrm{BTAH}_{(\mathrm{ads})}+\mathrm{O}_{\left(\mathrm{Cu}_{2} \mathrm{O}\right)} \rightarrow \mathrm{BTA}_{(\mathrm{ads})}+\mathrm{OH}_{(\mathrm{ads})}
$$

where $\mathrm{O}_{\left(\mathrm{Cu}_{2} \mathrm{O}\right)}$ is the $\mathrm{O}$ of the $\mathrm{Cu}_{2} \mathrm{O}$ surface. 

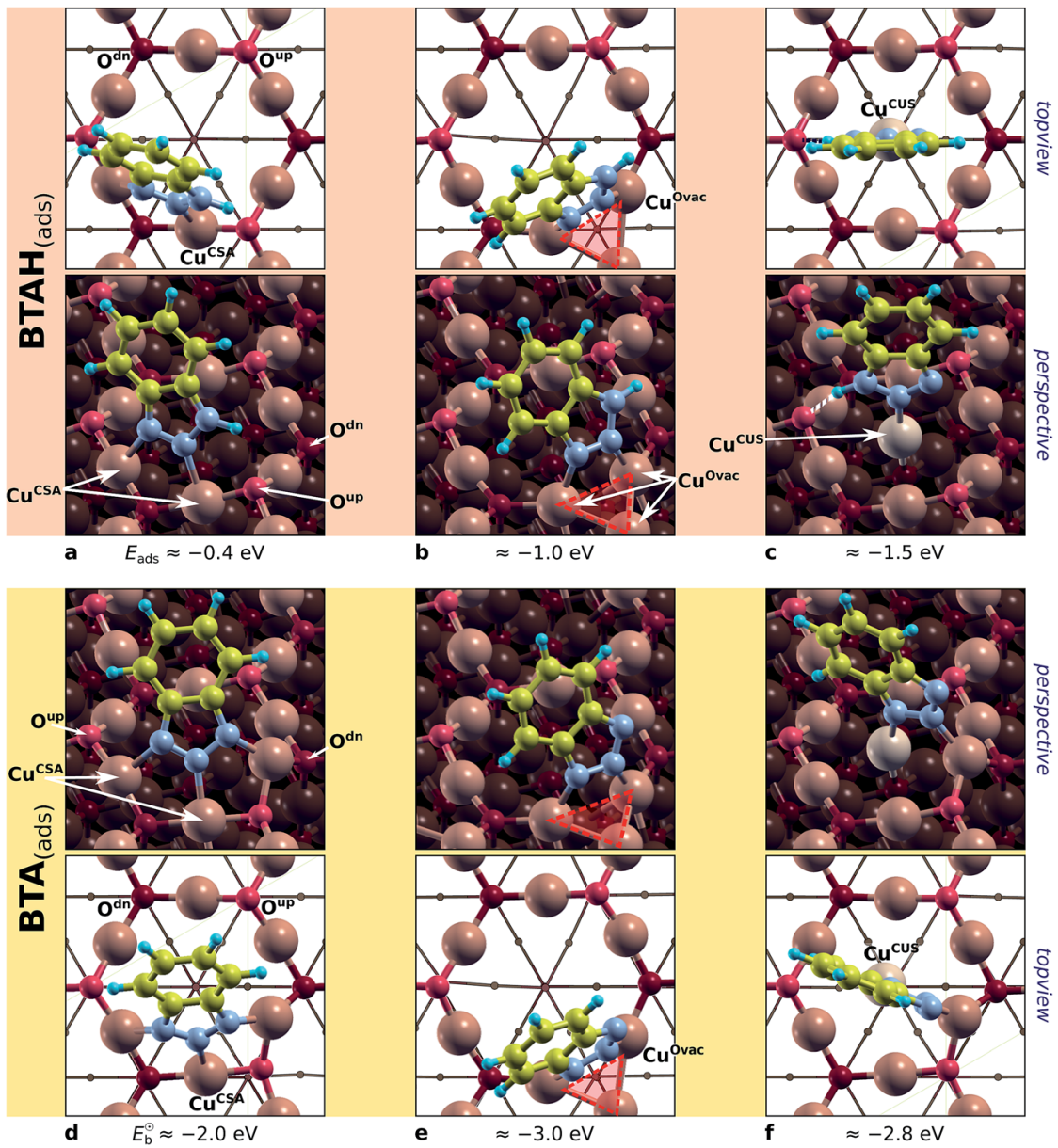

Fig. 8 Top-view and perspective plots of representative structures of $\mathrm{BTAH}_{\text {(ads) }}$ (top) and $\mathrm{BTA}_{\text {(ads) }}$ (bottom) on various considered sites of $\mathrm{Cu}_{2} \mathrm{O}$ (111); partially based on ref. 49 and 50. Adsorption (binding) energies are also reported. From left to right: molecular bonding

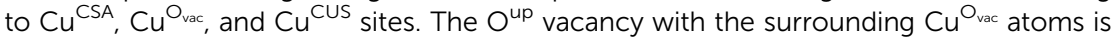
indicated by reddish triangle. Note that in addition to direct $\mathrm{N}-\mathrm{Cu}$ bonds, the BTAH adsorbed at $\mathrm{Cu}^{\mathrm{CUS}}$ also forms the $\mathrm{N} 1-\mathrm{H} \cdots \mathrm{O}^{\text {up }}$ hydrogen bond.

$\mathrm{Cu}^{\text {ad }}$ atoms is taken into account $\left(\mathrm{Cu}^{\text {ad }}\right.$ stands for $\mathrm{Cu}$ adatom), then the formation energies are in the range of $[-2.7,-1.4],[-2.7,-1.8]$, and $[-2.6,-1.7]$ eV per BTA for monomer, dimer, and polymer complex, respectively, where the lower number corresponds to $\mu_{\mathrm{Cu}}^{\max }$ and the upper number to $\mu_{\mathrm{Cu}}^{\min }$ (chemical potentials $\mu_{\mathrm{Cu}}^{\max }$ and $\mu_{\mathrm{Cu}}^{\min }$ are defined in the footnote of Section 4.1.3). For comparison, the formation energy of $\mathrm{BTA}_{(\mathrm{ads})}$ bonded to $\mathrm{Cu}^{\mathrm{CUS}}$ is in the range of $[-2.4,-1.7,] \mathrm{eV}$.

\subsection{Hydroxylated $\mathrm{Cu}_{2} \mathrm{O}(111)$ surfaces}

According to current calculations the $\mathrm{OH}$ bonds by about $1.9 \mathrm{eV}$ to $\mathrm{Cu}^{\mathrm{CSA}}, 3 \mathrm{eV}$ to $\mathrm{Cu}^{\mathrm{CUS}}$, and $3.6 \mathrm{eV}$ to $\mathrm{Cu}^{\mathrm{O}_{\text {vac }}}$ (with respect to $\mathrm{OH}$ radical in the gas-phase). Bonding 

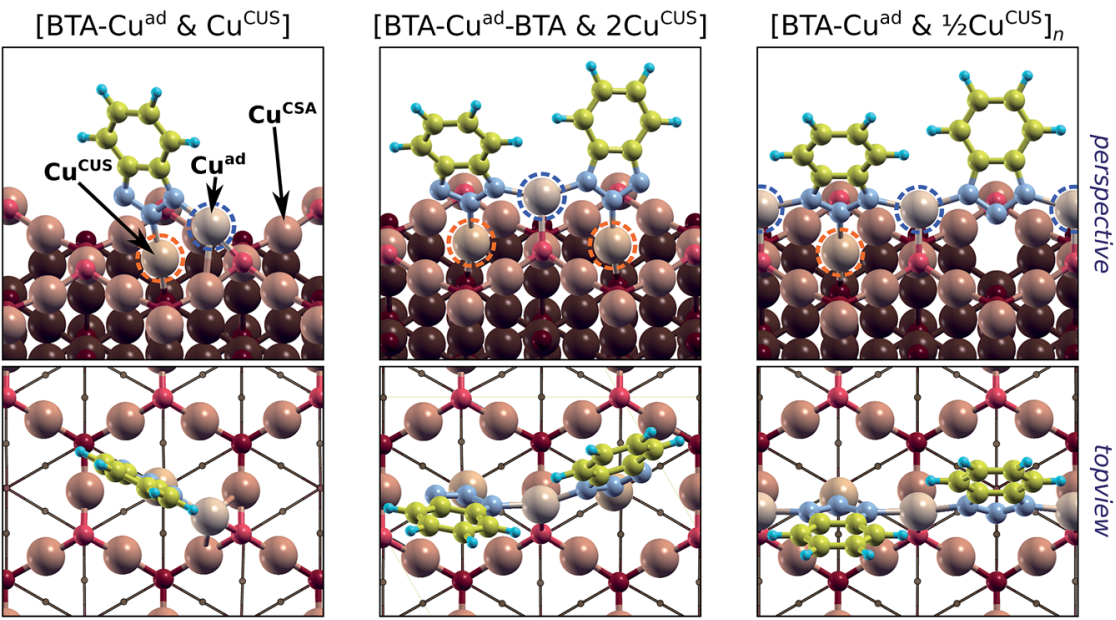

Fig. 9 Various BTA-Cu organometallic complexes on $\mathrm{Cu}_{2} \mathrm{O}(111)-w / o-\mathrm{Cu}^{\mathrm{CUS}}$ (perspective and top-view). From left to right: [BTA-Cu ${ }^{\text {ad }} \& \mathrm{Cu}^{\mathrm{CUS}}$ ] monomer, $\left[\mathrm{BTA}-\mathrm{Cu}^{\mathrm{ad}}-\mathrm{BTA} \&\right.$ $\left.2 \mathrm{Cu}^{\mathrm{CUS}}\right]$ dimer, and $\left[\mathrm{BTA}-\mathrm{Cu}^{\text {ad }} \& \frac{1}{2} \mathrm{Cu} \text { CUs }\right]_{n}$ polymer. $\mathrm{Cu}^{\text {ad }}$ stands for $\mathrm{Cu}$ adatom that is located above the surface and is incorporated into the complex. Note that, in addition to $\mathrm{Cu}^{\text {ad }}$, complexes also involve the $\mathrm{Cu}^{\mathrm{CUS}}$ atom(s). The naming of complexes reveals the stoichiometry between BTA, $\mathrm{Cu}^{\text {ad }}$, and $\mathrm{Cu}^{\mathrm{CUS}}$. The $\mathrm{Cu}^{\text {ad }}$ and $\mathrm{Cu}^{\mathrm{CUS}}$ are highlighted by dashed blue and orange circles, respectively.

enhancement is thus considerable-a trend similar to $\mathrm{BTA}_{(\mathrm{ads})}(c f$. Section 4.1.4). This enhancement helps us understand why, in contrast to gas-phase ambient, at water/solid interface the $\mathrm{Cu}_{2} \mathrm{O}$ surface can contain appreciable amounts of coordinatively unsaturated $\mathrm{Cu}$ ions, which are stabilized by adsorbates such as hydroxyls ${ }^{52}$ or inhibitor molecules (if present).

Two simple models of the hydroxylated surface of $\mathrm{Cu}_{2} \mathrm{O}$ were used, one derived from $\mathrm{Cu}_{2} \mathrm{O}(111)-w / o-\mathrm{Cu}^{\mathrm{CUS}}$ and the other from $\mathrm{Cu}_{2} \mathrm{O}(111): \mathrm{Cu}$.||| The first can be seen as a model of hydroxylated surface without (or an insignificant amount of) unsaturated $\mathrm{Cu}$ ions and the second as a model with considerable amounts of unsaturated $\mathrm{Cu}$ ions. Both models give rather similar benzotriazole-surface binding energies, which are about $-1.0 \mathrm{eV}$ for $\mathrm{BTAH}_{(\mathrm{ads})}(\mathrm{a}$ value similar to the one obtained on $\mathrm{Cu}^{\mathrm{O}_{\text {vac }}}$ sites of plain $\mathrm{Cu}_{2} \mathrm{O}(111)$ surface) and about $-3.8 \mathrm{eV}$ for $\mathrm{BTA}_{(\mathrm{ads})}$ (Fig. 10a and b). $\mathrm{BTA}_{(\mathrm{ads})}$ thus binds considerably stronger to the hydroxylated surface than to plain $\mathrm{Cu}_{2} \mathrm{O}$. Consequently, the dissociation of benzotriazole is favored on hydroxylated surfaces. Calculations further reveal that benzotriazole forms hydrogen bonds with the $\mathrm{OH}_{(\text {ads })}$ more efficiently than with the $\mathrm{O}^{\text {up }}$ ions of plain $\mathrm{Cu}_{2} \mathrm{O}$. The reason is that hydroxyls are much more flexible than $\mathrm{O}$ ions and can easily adjust so as to form hydrogen bonds with benzotriazole's $\mathrm{N}$ atoms (see Fig. 10). The flexibility of $\mathrm{OH}$ groups

||| The $\mathrm{Cu}_{2} \mathrm{O}(111)-\mathrm{w} / \mathrm{o}-\mathrm{Cu}^{\text {cus }}$ derived model was made hydroxylated by substituting all $\mathrm{O}^{\text {up }}$ and all $\mathrm{O}$ ions below the $\mathrm{Cu}^{\mathrm{CUS}}$ vacancies with $\mathrm{OH}$ groups; the model contains 8 hydroxyls per $(2 \times 2)$ supercell. For the $\mathrm{Cu}_{2} \mathrm{O}(111): \mathrm{Cu}$ the model as used by Asthagiri et al. ${ }^{58}$ was used, where the $\mathrm{Cu}_{2} \mathrm{O}(111): \mathrm{Cu}-(2 \times 2)$ supercell contains 4 hydroxyls, which bridge the $\mathrm{Cu}^{\mathrm{CUS}}$ and $\mathrm{Cu}^{\mathrm{O}_{\text {vac }}}$ ions. 

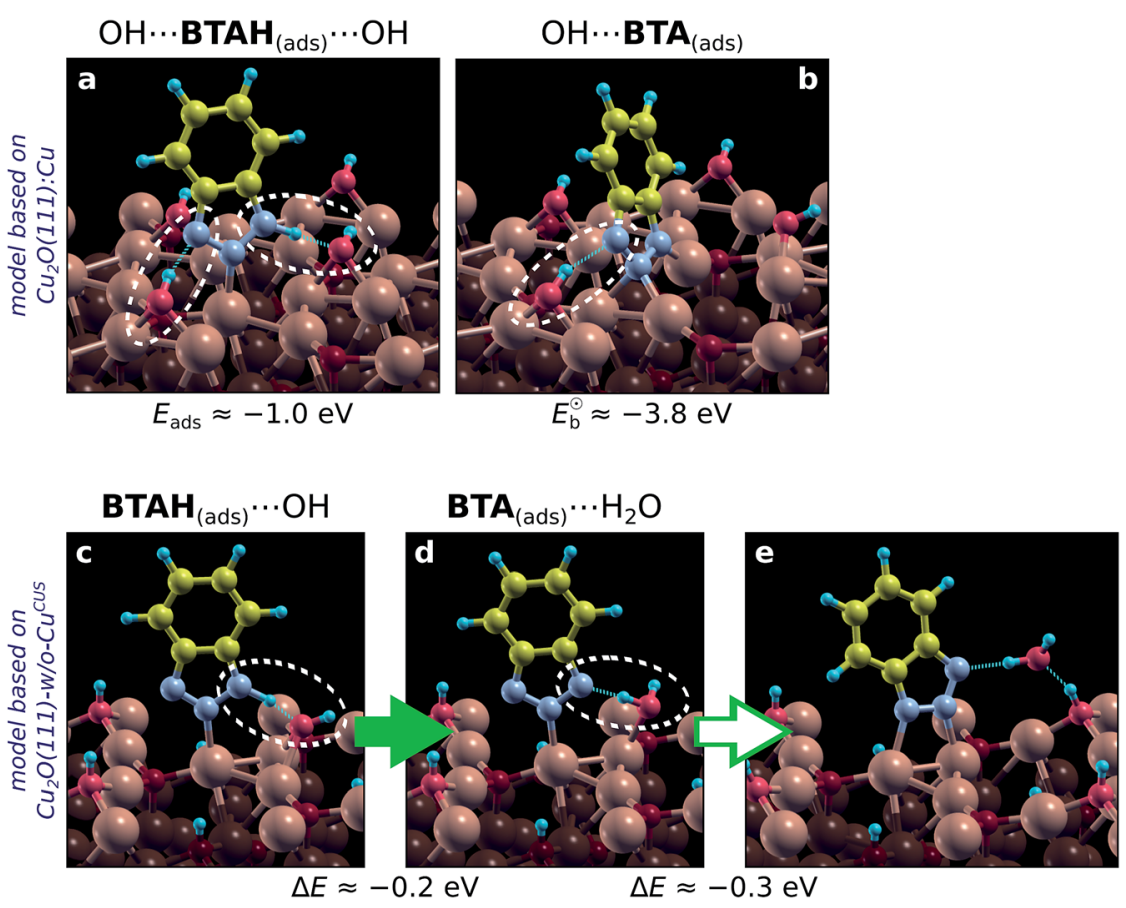

Fig. 10 Adsorption structures of $\mathrm{BTAH}_{(\text {ads })}$ and $\mathrm{BTA}_{(\text {ads })}$ on two different models of hydroxylated $\mathrm{Cu}_{2} \mathrm{O}(111)$ surface (refer to the text). The adsorption (binding) energies are also reported in ( $\mathrm{a}$ and $\mathrm{b}$ ). Note that in addition to direct $\mathrm{N}-\mathrm{Cu}$ bonding, benzotriazole also forms hydrogen-bonds with adsorbed hydroxyls (i.e., $\mathrm{OH} \cdots \mathrm{N}$ and/or $\mathrm{NH} \cdots \mathrm{OH}$ bonds), which are indicated by white dashed ellipses. (c and d) Dissociation of adsorbed BTAH by the proton transfer from its $\mathrm{N} 1$ atom to $\mathrm{OH}_{\text {(ads) }}$; the corresponding process is exothermic by $0.2 \mathrm{eV}$. (e) The $\mathrm{BTA}_{\text {(ads) }} \cdots \mathrm{H}_{2} \mathrm{O}_{\text {(ads) }}$ can further stabilize by $0.3 \mathrm{eV}$ by forming another $\mathrm{N}-\mathrm{Cu}$ bond and $\mathrm{H}_{2} \mathrm{O} \cdots \mathrm{OH}$ hydrogen bond (but the $\mathrm{H}_{2} \mathrm{O} \cdots \mathrm{Cu}$ bond is lost).

also leads to a new dissociation mechanism of benzotriazole. Namely, in addition to dissociation reaction (14), benzotriazole can also dissociate by interacting with the hydroxyl and forming a water molecule in the course of dissociation:

$$
\mathrm{BTAH}_{(\mathrm{ads})}+\mathrm{OH}_{(\mathrm{ads})} \rightarrow \mathrm{BTA}_{(\mathrm{ads})}+\mathrm{H}_{2} \mathrm{O}
$$

A snapshot of this reaction is shown in Fig. 10c and d. The corresponding elementary dissociative step is exothermic by $0.2 \mathrm{eV}$, but notice that the resulting $\mathrm{BTA}_{(\mathrm{ads})}$ structure (Fig. 10d) is not the stablest possible; the $\mathrm{BTA}_{(\mathrm{ads})}$ then further stabilizes by $0.3 \mathrm{eV}$ by forming another $\mathrm{N}-\mathrm{Cu}$ bond. Water formation has been proposed to form during BTAH dissociation in the literature, although due to interaction with oxygen. ${ }^{16,62}$

\section{Conclusions}

Controversial suggestions exist in the literature, concerning the role of copper oxides for the adsorption of benzotriazole. ${ }^{11}$ To shed some new light onto this 
question, the adsorption behavior of benzotriazole on reduced and oxidized copper surfaces was discussed on the basis of DFT results. DFT calculations reveal that benzotriazole is able to bond with oxide-free and oxidized copper surfaces. Its bonding is considerably enhanced on passing from $\mathrm{Cu}(111)$ to low coordinated defects on oxide-free surfaces. The bonding of aggressive chloride anions enhances in the same direction, but to a lesser extent. On oxide surfaces benzotriazole bonds considerably stronger to coordinatively unsaturated $\mathrm{Cu}$ sites. This suggests that benzotriazole is able to passivate the reactive under-coordinated surface sites that are plausible microscopic sites for corrosion attack.

The adsorption behavior of benzotriazole is non-trivial, because it can adsorb (at least in principle) in a variety of different forms. Perhaps this is one of the strengths of benzotriazole; depending on different conditions it adopts one of several possible forms and thus sustains various situations. However, benzotriazole chemisorbs strongly only in the deprotonated form. Gross bonding is even stronger when BTA is incorporated into BTA-Cu organometallic adcomplexes. DFT results are therefore consistent with experimental evidence that the ability of benzotriazole to inhibit corrosion is due to the formation of organometallic complexes. This readily explains why benzotriazole is more effective at higher $\mathrm{pH}$ values. Namely, at low $\mathrm{pH}$ (and low potentials) the BTA transforms to $\mathrm{BTAH}_{(\mathrm{ads})},{ }^{47}$ which is bonded considerably weaker to the surface and may eventually desorb; according to the calculations the most strongly bonded adsorption form under such conditions is the BTAH physisorbed parallel to the surface and intermolecularly connected into a H-bonding network with other BTAH molecules. $* * *$

Strong inhibitor-surface bonding, as important as it may be, is by no means the only relevant factor for corrosion inhibition. $\mathrm{BTAH}_{\perp},[\mathrm{BTA}-\mathrm{Cu}-\mathrm{BTA}]$ and $[\mathrm{BTA}-\mathrm{Cu}]_{n}$ considerably reduce the metal work function, which is a consequence of a large permanent molecular dipole and a properly oriented adsorption structure. It has been argued that such a pronounced effect on the work function should make any reaction that donates electron(s) to the metal less favorable (e.g., $\mathrm{Cl}_{\text {(solv) }}^{-} \rightarrow \mathrm{Cl}_{(\mathrm{ads})}+\mathrm{e}_{(\text {metal })}^{-}$or $\mathrm{Cu}_{(\text {solid })} \rightarrow \mathrm{Cu}_{(\text {solv })}^{n+}+n \mathrm{e}_{(\text {metal })}^{-}$. This reasoning is consistent with the fact that benzotriazole predominantly affects the anodic reaction, although it is a mixed type inhibitor. ${ }^{11,63} \mathrm{~A}$ large permanent molecular dipole is a general characteristic of azoles [e.g., imidazole (3.8 D), triazole (4.4 D), tetrazole $(5.4 \mathrm{D})]{ }^{4}{ }^{4}$ A mechanism based on the reduction of work function may be therefore operative also for other azole inhibitors. There are, however, significant differences between imidazole and triazole/tetrazole based inhibitors. Our recent DFT calculations suggest that imidazoles are active against corrosion in neutral molecular form, while tetrazoles-similar to triazoles-inhibit the corrosion in their deprotonated form. ${ }^{36}$ The reason for the different behaviour of imidazoles is two fold; the first is due to their more basic nature and the second is related to

\footnotetext{
*** Only deprotonated $\mathrm{BTA}^{-}$and neutral BTAH were considered in this paper, because protonated $\mathrm{BTAH}_{2}{ }^{+}$seems not to be competitive. According to DFT calculations, $\mathrm{BTAH}_{2}{ }^{+}$bonds only marginally stronger than the neutral $\mathrm{BTAH}$ to $\mathrm{Cu}$ surfaces, ${ }^{26}$ but it solvates considerably stronger (for further DFT-based analysis of the adsorption of deprotonated, neutral, and protonated azoles, see our recent study ${ }^{36}$ ). This implies that $\mathrm{BTAH}_{2}{ }^{+}$prefers being solvated rather than adsorbed. It was reported that it is the dominant adsorbed form only at $\mathrm{pH} \lesssim 0 .^{62}$
} 
their molecular spatial structure, because of which they can form only one strong $\mathrm{N}-\mathrm{Cu}$ bond, while triazoles and tetrazoles can form at least two.

An ability to form soluble complexes with dissolved metal ions as well as the solubility of stand-alone inhibitor are also relevant in the context of corrosion. A formation of soluble complexes between inhibitors and metal ions would help increase the dissolution of metal, thus having the effect of promoting the corrosion. This effect has been characterized for several imidazole based inhibitors in our parallel study. ${ }^{64}$ As for the solubility, it is known that the more soluble the molecule is, the smaller is its (relative) affinity for adsorption. ${ }^{3}$ Ideas of a similar kind were very recently used by Mondal and Taylor, ${ }^{65}$ who described a clever approach towards a rational design of corrosion inhibitors.

Last but not least, the ability of a molecule to inhibit corrosion of a metal is also given by the chemical nature of the metal itself, because molecules bond differently to various metals. For example, while $\mathrm{Cu}$ and $\mathrm{Al}$ are not reactive enough to interact with the azoles' $\pi$ system, $\dagger \dagger \dagger$ Fe can readily do so. ${ }^{26}$ This can have a pronounced effect on the structure of the adsorbed molecule.

\section{Acknowledgements}

This work has been supported by the Slovenian Research Agency (Grant no. P20148). The author is indebted to several researchers, first and foremost to Prof. Ingrid Milošev for bringing the subject of corrosion inhibitors to his attention. Sebastijan Peljhan and Nataša Kovačević are acknowledged for their many calculations and useful discussions on the subject azoles on metal surfaces. Prof. Phillipe Marcus is acknowledged for enlightening discussion about the growth of oxides on metal surfaces and surface hydroxylation. Dunja Peca and Matic Poberžnik are acknowledged for their careful reading of the manuscript.

\section{References}

1 M. M. Antonijević and M. B. Petrović, Int. J. Electrochem. Sci., 2008, 3, 1-28.

2 G. Schmitt, Br. Corros. J., 1984, 19, 165-176.

3 J. O. Bockris and A. K. N. Reddy, Modern Electrochemistry, Kluwer Academic/ Plenum Publishers, New York, Boston, Dordrecht, London, Moscow, 2nd edn, 2000, vol. 2B.

4 N. Kovačević and A. Kokalj, J. Phys. Chem. C, 2011, 115, 24189-24197.

5 Y. Jiang and J. B. Adams, Surf. Sci., 2003, 529, 428-442.

6 S. Peljhan and A. Kokalj, Phys. Chem. Chem. Phys., 2011, 13, 20408-20417.

7 A. Kokalj, S. Peljhan, M. Finšgar and I. Milošev, J. Am. Chem. Soc., 2010, 132, 16657-16668.

8 S. Peljhan, J. Koller and A. Kokalj, J. Phys. Chem. C, 2014, 118, 933-943.

9 J. B. Cotton and I. R. Scholes, Br. Corros. J., 1967, 2, 1-5.

10 G. W. Poling, Corros. Sci., 1970, 10, 359-437.

11 M. Finšgar and I. Milošev, Corros. Sci., 2010, 52, 2737-2749.

12 D. Chadwick and T. Hashemi, Corros. Sci., 1978, 18, 39-51.

13 R. F. Roberts, J. Electron Spectrosc. Relat. Phenom., 1974, 4, 273-291.

$\dagger \dagger \mathrm{Cu}$ can do it only exceptionally: an example is the apparent chem + phys form of Fig. $1 \mathrm{~b}$ and even then the interaction is driven by the dispersion van der Waals forces. ${ }^{6}$ 
14 V. Brusic, M. A. Frisch, B. N. Eldridge, F. P. Novak, F. B. Kaufman, B. M. Rush and G. S. Frankel, J. Electrochem. Soc., 1991, 138, 2253-2259.

15 B.-S. Fang, C. G. Olson and D. W. Lynch, Surf. Sci., 1986, 176, 476-490.

16 G. Xue, J. Ding, P. Lu and J. Dong, J. Phys. Chem., 1991, 95, 7380-7384.

17 P. Giannozzi, S. Baroni, N. Bonini, M. Calandra, R. Car, C. Cavazzoni, D. Ceresoli, G. L. Chiarotti, M. Cococcioni, I. Dabo, A. D. Corso, S. de Gironcoli, S. Fabris, G. Fratesi, R. Gebauer, U. Gerstmann, C. Gougoussis, A. Kokalj, M. Lazzeri, L. Martin-Samos, N. Marzari, F. Mauri, R. Mazzarello, S. Paolini, A. Pasquarello, L. Paulatto, C. Sbraccia, S. Scandolo, G. Sclauzero, A. P. Seitsonen, A. Smogunov, P. Umari and R. M. Wentzcovitch, J. Phys.: Condens. Matter, 2009, 21, 395502.

18 D. Vanderbilt, Phys. Rev. B: Condens. Matter Mater. Phys., 1990, 41, 7892-7895. 19 A. Kokalj, J. Mol. Graphics Modell., 1999, 17, 176-179.

20 J. P. Perdew, K. Burke and M. Ernzerhof, Phys. Rev. Lett., 1996, 77, 3865-3868.

21 S. Grimme, J. Comput. Chem., 2006, 27, 1787-1799.

22 V. Barone, M. Casarin, D. Forrer, M. Pavone, M. Sambi and A. Vittadini, J. Comput. Chem., 2009, 30, 934-939.

23 A. Kokalj and S. Peljhan, Langmuir, 2010, 26, 14582-14593.

24 S. Peljhan and A. Kokalj, J. Phys. Chem. C, 2009, 113, 14363-14376.

25 X. Chen and H. Häkkinen, J. Phys. Chem. C, 2012, 116, 22346-22349.

26 N. Kovačević and A. Kokalj, Mater. Chem. Phys., 2012, 137, 331-339.

27 A. Kokalj, S. Peljhan and J. Koller, J. Phys. Chem. C, 2014, 118, 944-954.

28 F. Grillo, D. W. Tee, S. M. Francis, H. A. Früchtl and N. V. Richardson, J. Phys. Chem. C, 2014, 118, 8667-8675.

29 J. F. Walsh, H. S. Dhariwal, A. Gutirrez-Sosa, P. Finetti, C. A. Muryn, N. B. Brookes, R. J. Oldman and G. Thornton, Surf. Sci., 1998, 415, 423-432.

30 J. O. Nilsson, C. Tornkvist and B. Liedberg, Appl. Surf. Sci., 1989, 37, 306-326.

31 F. Grillo, D. W. Tee, S. M. Francis, H. Fruchtl and N. V. Richardson, Nanoscale, 2013, 5, 5269-5273.

32 A. Kokalj, Phys. Rev. B: Condens. Matter Mater. Phys., 2011, 84, 045418.

33 J. O. Bockris, A. K. N. Reddy and M. Gamboa-Aldeco, Modern Electrochemistry, Kluwer Academic/Plenum Publishers, New York, Boston, Dordrecht, London, Moscow, 2nd edn, 2000, vol. 2A.

34 M. T. M. Koper and R. A. van Santen, Surf. Sci., 1999, 422, 118-131.

35 S. Trasatti, Electrochim. Acta, 1991, 36, 1659-1667.

36 N. Kovačević and A. Kokalj, Corros. Sci., 2013, 73, 7-17.

37 A. Kokalj, Chem. Phys., 2012, 393, 1-12.

38 S. Trasatti and L. M. Doubova, J. Chem. Soc., Faraday Trans., 1995, 91, 33113325.

39 L. Doubova and S. Trasatti, Electrochim. Acta, 1997, 42, 785-791.

40 C. D. Taylor, S. A. Wasileski, J.-S. Filhol and M. Neurock, Phys. Rev. B: Condens. Matter Mater. Phys., 2006, 73, 165402.

41 M. J. Weaver, Appl. Surf. Sci., 1993, 67, 147-159.

42 M. T. M. Koper, R. A. van Santen, S. A. Wasileski and M. J. Weaver, J. Chem. Phys., 2000, 113, 4392-4407.

43 S. A. Wasileski, M. T. M. Koper and M. J. Weaver, J. Phys. Chem. B, 2001, 105, 3518-3530.

$44 \mathrm{~J}$. B. Cotton, Proceedings of the 2nd International Congress on Metallic Corrosion, New York, USA, 1963, pp. 590-596. 
45 J. C. Rubim, I. G. R. Gutz, O. Sala and W. J. Orville-Thomas, J. Mol. Struct.: THEOCHEM, 1983, 100, 571-583.

46 D. Chadwick and T. Hashemi, J. Electron Spectrosc. Relat. Phenom., 1977, 10, 79-83.

47 R. Youda, H. Nishihara and K. Aramaki, Electrochim. Acta, 1990, 35, 1011-1017.

48 Y. Jiang, J. B. Adams and D. Sun, J. Phys. Chem. B, 2004, 108, 12851-12857.

49 S. Peljhan, Ph.D. thesis, University of Ljubljana, 2012.

50 A. Kokalj and S. Peljhan, J. Phys. Chem. C, 2015, DOI: 10.1021/ acs.jpcc.5b01677.

51 V. Maurice and P. Marcus, Electrochim. Acta, 2012, 84, 129-138.

52 M. M. Islam, B. Diawara, V. Maurice and P. Marcus, Surf. Sci., 2009, 603, 20872095.

53 J. Kunze, V. Maurice, L. H. Klein, H.-H. Strehblow and P. Marcus, J. Phys. Chem. $B, 2001,105,4263-4269$.

54 V. Maurice, H.-H. Strehblow and P. Marcus, Surf. Sci., 2000, 458, 185-194.

55 A. Soon, M. Todorova, B. Delley and C. Stampfl, Phys. Rev. B: Condens. Matter Mater. Phys., 2007, 75, 125420.

56 A. Soon, M. Todorova, B. Delley and C. Stampfl, Phys. Rev. B: Condens. Matter Mater. Phys., 2007, 76, 129902.

57 A. Önsten, M. Göthelid and U. O. Karlsson, Surf. Sci., 2009, 603, 257-264.

58 X. Nie, G. L. Griffin, M. J. Janik and A. Asthagiri, Catal. Commun., 2014, 52, 8891.

59 P. W. Tasker, J. Phys. C: Solid State Phys., 1979, 12, 4977-4984.

60 L. D. Hansen, B. D. West, E. J. Baca and C. L. Blank, J. Am. Chem. Soc., 1968, 90, 6588-6592.

61 M. Finšgar, J. Kovač and I. Milošev, J. Electrochem. Soc., 2010, 157, C52-C60.

62 H. Y. H. Chan and M. J. Weaver, Langmuir, 1999, 15, 3348-3355.

63 M. Finšgar, A. Lesar, A. Kokalj and I. Milošev, Electrochim. Acta, 2008, 53, 82878297.

64 N. Kovačević, I. Milošev and A. Kokalj, Corros. Sci., 2015, submitted.

65 S. K. Mondal and S. R. Taylor, J. Electrochem. Soc., 2014, 161, C476-C485. 